\title{
Las cuencas cenozoicas y su control en el volcanismo de los Complejos Nevados de Chillán y Copahue-Callaqui (Andes del Sur, 36-395)
}

\begin{abstract}
Juan Pablo Radic
Enap-Sipetrol S.A., Av. Vitacura 2736, Las Condes, Santiago, Chile.

jradic@sipetrol.cl

RESUMEN. La Cordillera Principal de los Andes entre los $36^{\circ}$ y $39^{\circ} \mathrm{S}$ constituye un excelente lugar para el estudio de la relación entre volcanismo y tectónica. Por medio del análisis tectonoestratigráfico de las cuencas cenozoicas se ha podido reconocer una clara coincidencia espacial entre estructuras de primer orden pertenecientes a estas cuencas y la distribución del volcanismo plio-pleistocénico. Las cuencas cenozoicas comenzaron su desarrollo durante el Oligoceno-Mioceno como depresiones extensionales, conformando un sistema de al menos tres subcuencas orientadas $\mathrm{N}-\mathrm{S}$ y conectadas por dos zonas de acomodación estructural. Posteriormente este sistema de cuencas fue tectónicamente invertido hacia finales del Mioceno y los antiguos depocentros fueron deformados y exhumados, reutilizando las fallas originalmente extensionales. Las zonas de acomodación estructural permanecieron como estructuras de primer orden a escala de cuenca y constituyeron zonas de debilidad que favorecieron el posterior desarrollo del volcanismo y magmatismo en los complejos volcánicos Nevados de Chillán y Copahue-Callaqui. Cada uno de estos complejos volcánicos se caracteriza por una orientación de sus centros de emisión, morfología y depósitos volcánicos en forma subparalela a la orientación de las zonas de acomodación estructural inmediatamente por debajo.
\end{abstract}

Palabras clave: Andes, Chile, Cuenca de Cura-Mallin, 'Rift', Inversión, Volcanismo, Tectónica.

\begin{abstract}
Cenozoic basins and their control on volcanism of Nevados de Chillán and Copahue-Callaqui complexes (36-39 ${ }^{\circ} \mathrm{S}$, Southern Andes). The Cordillera Principal at $36^{\circ}$ to $39^{\circ} \mathrm{S}$ is an excellent place to address the relationship between tectonics and volcanism. Based on tectonostratigraphic analysis of the Cenozoic basins it has been possible to recognize a clear spatial coincidence between first order basin scale structures and Plio-Pleistocene volcanism. Cenozoic basins started in the Oligocene-Miocene as extensional depocenters, characterized by at least three north-south oriented sub-basins connected by two structural accommodation zones. Towards the Late Miocene this extensional system was tectonically inverted deforming and uplifting the previous extensional faults and sedimentary fill. The accommodation zones prevailed as first order structures and acted as weakened zones that enabled the volcanism and magmatism at the Nevados de Chillán and Copahue-Callaqui volcanic complexes. Each one of these volcanic complexes is characterized by an oriented series of emission centers, volcanic morphology and deposits that are subparallel to the underlying accommodation zone.
\end{abstract}




\section{Introducción}

La relación entre la estructura del sustrato y la distribución espacial del volcanismo aún está relativamente poco entendida para diversos ambientes geológicos, debido a que normalmente los depósitos volcánicos asociados enmascaran dichas estructuras. Durante las últimas décadas se ha avanzado bastante en el entendimiento de la importancia de dicha interacción, siendo hoy en día generalmente aceptada la relación entre la morfología de los edificios volcánicos, la orientación de diques y la distribución de conos adventicios, entre otros, con el estado de esfuerzo regional y local, así como también las estructuras heredadas (Nakamura, 1977; Tibaldi, 1995; Acocella et al., 1999, 2002; Pasquaré y Tibaldi, 2003). En este contexto, la Cordillera de los Andes entre los $36^{\circ}$ y los $39^{\circ} \mathrm{S}$ representa un segmento del orógeno andino bastante favorable para el estudio de la volcanotectónica, así como la recurrencia de la deformación en la evolución geológica.

En el presente trabajo se integran los datos del estudio de las cuencas oligo-miocenas realizado en este sector de los Andes y se presentan los antecedentes que han permitido interpretar una relación directa entre las anisotropías heredadas del sustrato con la distribución del volcanismo plio-pleistocénico de los complejos Nevados de Chillán (CVCh) y Copahue-Callaqui (CVCC), en concordancia con lo documentado anteriormente en varios trabajos dentro del área (López-Escobar et al., 1995; Cembrano y Moreno, 1994; Lara et al., 2004; Melnick et al., 2006a).

La metodología de trabajo incluyó mapeos a escala 1:100.000 realizados localmente en las zonas del volcán Chillán, alto del río Queuco, laguna del Barco, y Lonquimay, los cuales fueron integrados con los mapas regionales a escala 1:250.000 publicados en las hojas de laguna del Maule, laguna del Laja y Curacautín (Muñoz y Niemeyer, 1984; Niemeyer y Muñoz, 1983; Suárez y Emparan, 1997), y los mapas realizados por Burns (2002); Folguera et al. (2006a, b, 2007); Pesce (1981) y Melnick et al. (2006a). Además, se realizó el análisis tectonoestratigráfico de las cuencas cenozoicas y se construyeron secciones estructurales en cada una de las subcuencas.

\section{Marco geológico regional}

El área de estudio se encuentra localizada en los Andes del Sur entre los $36^{\circ}$ y los $39^{\circ} \mathrm{S}$ y es parte de la zona volcánica central del sur de Chile $\left(27^{\circ}-38^{\circ} \mathrm{S}\right)$ (Stern, 2004; Charrier et al., 2007; López-Escobar et al., 1995). A grandes rasgos este sector se caracteriza por una serie de unidades morfoestructurales de orientación general N-S, entre las que se encuentran la Cordillera de la Costa, el Valle Central, la Cordillera Principal (incluyendo el arco magmático actual y el retroarco) y la cuenca de antepaís, siendo el foco de este trabajo la Cordillera Principal (Fig. 1). La evolución geológica de la zona de estudio abarca al menos desde el Triásico en adelante y está íntimamente ligada al desarrollo de la cuenca Neuquina. Dicha evolución se caracteriza por un estado inicial de cuenca extensional de 'rift' del Triásico-Jurásico Inferior, seguido por un período de subsidencia termal entre el Jurásico Superior-Cretácico Inferior y finalmente por un estado compresivo que desarrolló una faja plegada y una cuenca de antepaís desde el Cretácico Superior en adelante (Vergani et al., 1995).

Durante el Oligoceno-Mioceno la zona de estudio fue afectada por el desarrollo de la cuenca extensional de Cura-Mallín, sobreimpuesta a la porción occidental de la faja plegada neuquina, y tectónicamente invertida hacia el Mioceno Superior (Jordan et al., 2001; Burns, 2002; Radic et al., 2002; Folguera et al., 2002, 2003). Sin embargo, existen algunos trabajos que han objetado este evento extensivo argumentando que la cuenca de Cura-Mallín correspondería a una cuenca de intramontana (Cobbold y Rossello, 2003; Cobbold et al., 2008).

A partir del Plioceno, la Cordillera Principal en la zona del retroarco fue afectada por una tectónica extensional (Cuenca de Cola de Zorro, Folguera et al., 2003, 2006b), mientras que su contraparte en el intraarco era afectada por una tectónica transcurrente de máximo esfuerzo horizontal principal NE-SO que actuó desde el Pleistoceno hasta ahora (Lavenu y Cembrano, 1999; Melnick et al., 2006a). La deformación está controlada principalmente por la zona de falla de Liquiñe-Ofqui (ZFLO, Lavenu y Cembrano, 1999) (Fig. 1).

\section{Las cuencas extensionales oligo-miocenas}

Durante el Oligoceno-Mioceno el área de estudio estuvo dominada por un sistema de cuencas extensionales de 'rift' continental con dominio de rocas piroclásticas (Carpinelli, 2000; Jordan et al., 2001; Radic et al., 2002; Melnick et al., 2006b; Burns, 2002, 2006; Folguera et al., 2003). Estas cuencas se 


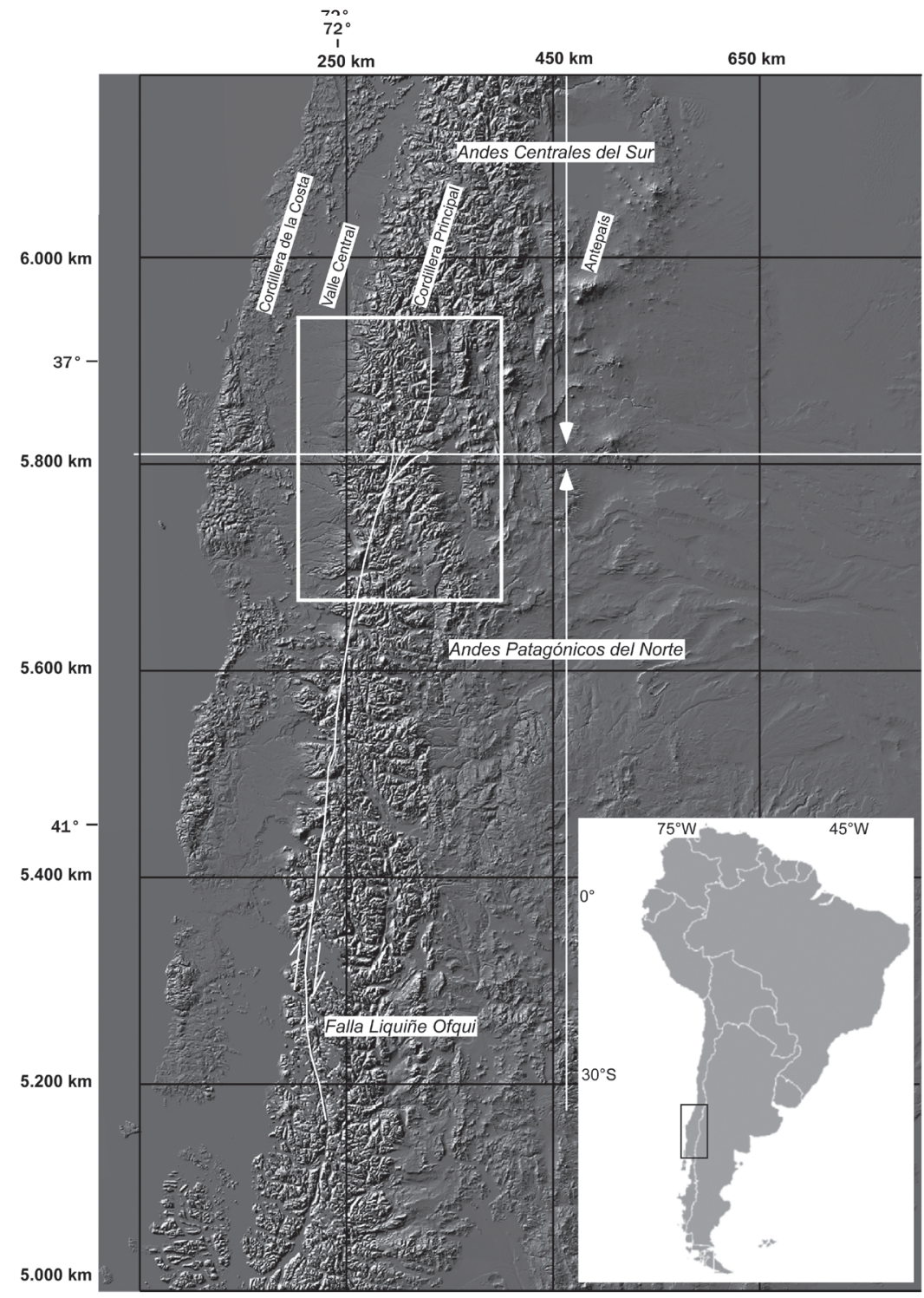

FIG. 1. Mapa de ubicación de la zona de estudio dentro del límite entre los Andes Centrales del Sur y los Andes Patagónicos, basado en el modelo de elevación digital obtenido a partir de los datos de SRTM-NASA. Principales unidades morfoestructurales de la cordillera entre $\operatorname{los} 36^{\circ}$ y $39^{\circ} \mathrm{S}$. Rectángulo muestra la zona de estudio.

desarrollaron por sobre un basamento poco conocido y que además presenta solo algunos pocos lugares de afloramiento. Entre estos destacan rocas sedimentarias marinas jurásicas de la parte más occidental de la cuenca neuquina (Formación Nacientes del Bío-Bío, De la Cruz y Suárez, 1997), rocas ígneas de edad cretácica (Intrusivos de la Cordillera Andina, Ferraris,
1981; Complejo Plutónico Galletué, Suárez y Emparan, 1997) y rocas sedimentarias y volcánicas de edad cretácica superior-terciaria inferior (Unidad El Sauce, IIG/MMAJ, 1979'; Estratos de Polcura-Cholguán, Ferraris, 1981; Complejo Vizcacha-Cumilao, Suárez y Emparan, 1997; Serie Andesítica, Groeber, 1956; Rapela y Llambías, 1985) (Fig. 2).

\footnotetext{
Instituto de Investigaciones Geológicas/Metal Minning Agency of Japan. 1979. Informe de reconocimiento geológico de la región Andina situada al este de la ciudad de Concepción (Inédito), Fase 1, 281 p. Santiago.
} 
El relleno del sistema extensional está representado por las formaciones Cura-Mallín en Chile y Epulauquen en Argentina (González y Vergara, 1962; Niemeyer y Muñoz, 1983; Muñoz y Niemeyer, 1984; Suárez y Emparan, 1997; Pesce, 1981; Zanettini, 1987), el cual está caracterizado principalmente por facies volcánicas y volcanoclásticas distribuidas de acuerdo a la proximidad de los paleocentros volcánicos.

Sobreyaciendo concordantemente a las unidades mencionadas se dispone una secuencia volcánica conocida como formación Trapa-Trapa y Mitrauquén en Chile (Niemeyer y Muñoz, 1983; Suárez y Emparan, 1997) y Cajón Negro y Quebrada Honda en Argentina (Pesce, 1981). Debido a que su distribución se extiende sobrepasando los límites de las unidades previas y, además, presentando poca variación en su espesor, es que no ha sido conside- rada como parte del relleno de la etapa extensional de la cuenca.

\subsection{Geometría interna del sistema de cuencas}

Una característica geométrica reconocida en muchas cuencas extensionales alrededor del mundo corresponde a la compartimentalización interna del sistema en subcuencas y la forma en que estas se encuentran ligadas a lo largo del rumbo. Las subcuencas se caracterizan por una geometría asimétrica de hemigraben, las cuales representan la unidad fundamental del sistema de cuencas de 'rift'. El relevo entre unidades adyacentes ocurre a través de zonas de acomodación o transferencia estructural que permiten el balance de la extensión y los cambios en polaridad (Rosendhal, 1987; Morley et al., 1990). Los

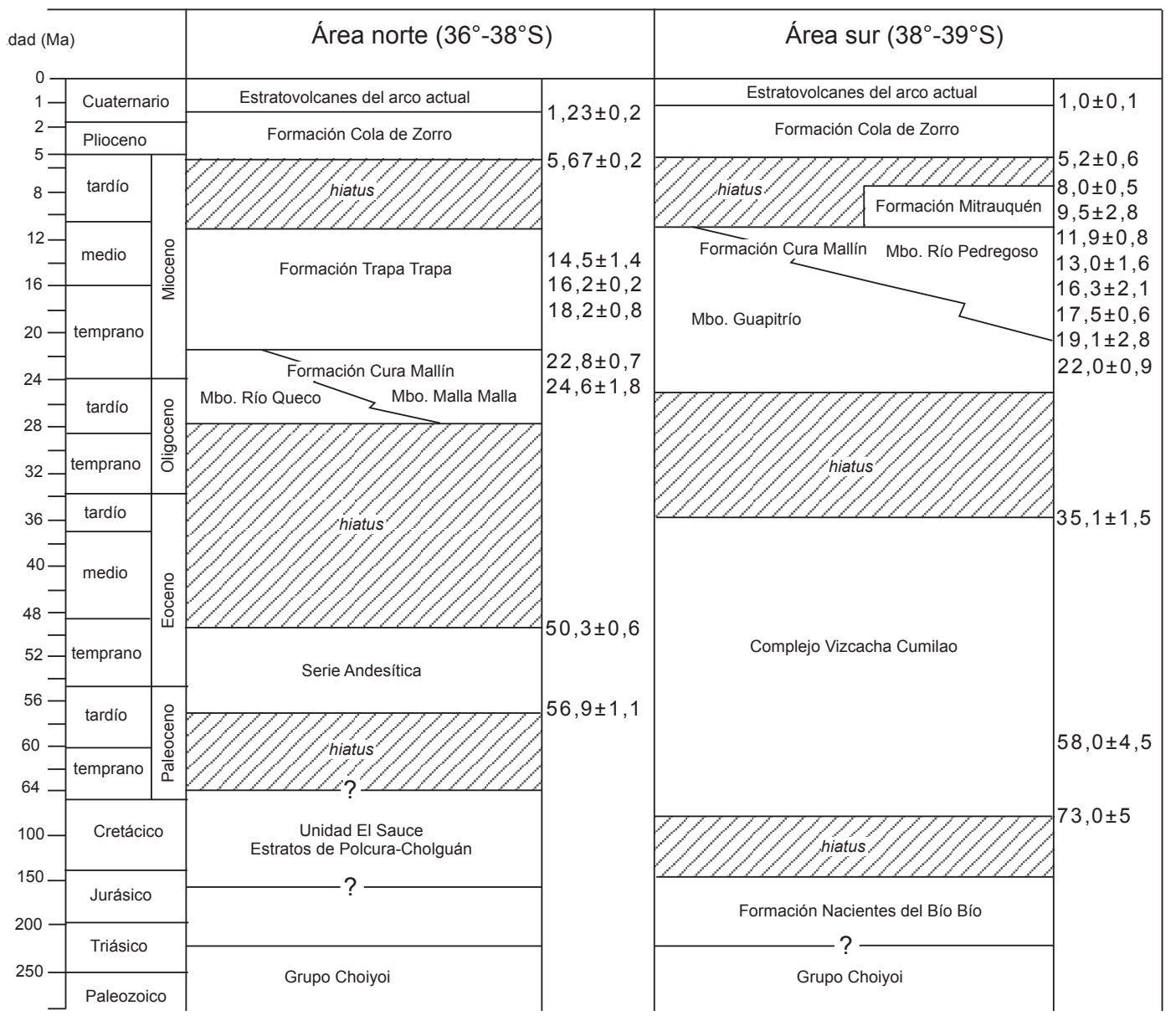

FIG. 2. Cuadro cronoestratigráfico generalizado (modificado de Melnick et al., 2006b). 

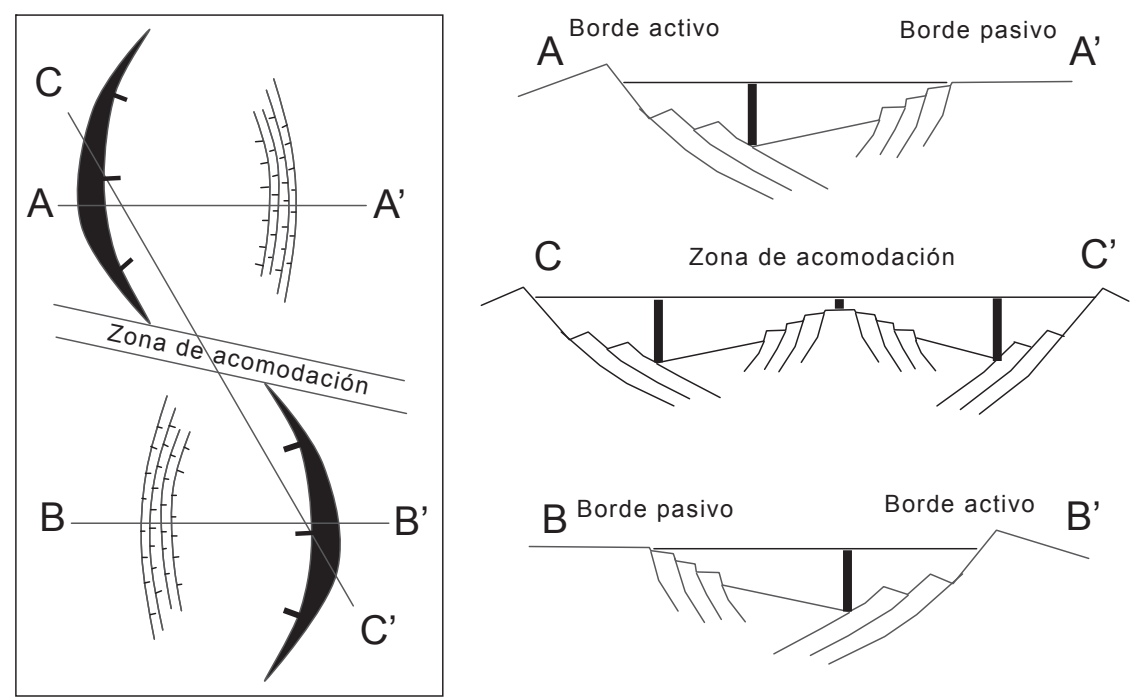

FIG. 3. Vista en planta y sección hipotética de un par de hemigrábenes sucesivos con una zona de acomodación estructural desarrollada entre ambos. La línea vertical gris en las secciones muestra el espesor del relleno sedimentario. Tomado de Rosendahl (1987).

hemigrábenes normalmente presentan dimensiones de alrededor de $80-160 \mathrm{~km}$ de largo por $40-80 \mathrm{~km}$ de ancho y representan unidades estructurales y depositacionales independientes. Ambos bordes se encuentran fallados, sin embargo, el mayor salto de falla y la mayor generación de espacio se encuentra localizada sobre el 'borde activo', dándole su característica asimétrica (Fig. 3). El piso de la cuenca generalmente se encuentra fallado en bloques de 5 a $10 \mathrm{~km}$ de ancho y además segmentado a lo largo del rumbo por una serie de fallas oblicuas de distinto espaciamiento.

El sistema de 'rift' de Cura-Mallín se caracteriza por al menos tres subcuencas diacrónicas e independientes, las cuales han sido denominadas en este trabajo de sur a norte como subcuenca Chillán, Lileo y Lonquimay respectivamente y a continuación se describen.

\subsubsection{Subcuenca Chillán}

La subcuenca Chillán se extiende entre el Nevados del Longaví por el norte y el Complejo Volcánico Nevados de Chillán (CVCh) por el sur. Se caracteriza por una orientación general norte-sur, un largo de $70 \mathrm{~km}$ y un ancho de $60 \mathrm{~km}$ aproximadamente. $\mathrm{Su}$ arquitectura extensional está caracterizada por un hemigraben de polaridad al oeste con el borde activo ubicado en el sector de Coihueco-Recinto en territorio chileno y un borde pasivo que se encuentra en las cercanías de las lagunas de Epulauquen en territorio argentino (Fig. 4). Si bien las fallas de borde de la subcuenca Chillán no han sido reconocidas en terreno, estas han sido inferidas a partir del límite de los afloramientos, espesor y distribución de los ambientes sedimentarios de las rocas del relleno, asimetría de subcuencas adyacentes y coincidencia con las estructuras compresivas desarrolladas durante el evento de inversión tectónica del Mioceno Tardío. Además, estas estructuras compresivas también han sido utilizadas para interpretar parte del sistema de fallas del arreglo extensional al interior de la subcuenca, bajo el supuesto de que todas ellas correspondan a inversión tectónica de fallas previas.

A grandes rasgos y con los datos que se tienen hasta ahora, las rocas que conforman el relleno de la subcuenca de Chillán se caracterizan por una geometría asimétrica de cuña. Sobre el borde activo, el relleno de la subcuenca está representado por una columna de más de $2.500 \mathrm{~m}$ de rocas volcánicas y volcanoclásticas pertenecientes a la Formación CuraMallín, agrupadas en dos miembros principales y sin base reconocida (Muñoz y Niemeyer, 1984) (Fig. 5). El miembro inferior volcánico ha sido denominado miembro Río Queuco y está integrado por tobas, brechas y subordinadamente areniscas, conglomerados, lutitas y coladas de lavas andesíticas. Inmediatamente por sobre las volcanitas del miembro Río Queuco se dispone en concordancia el miembro superior 


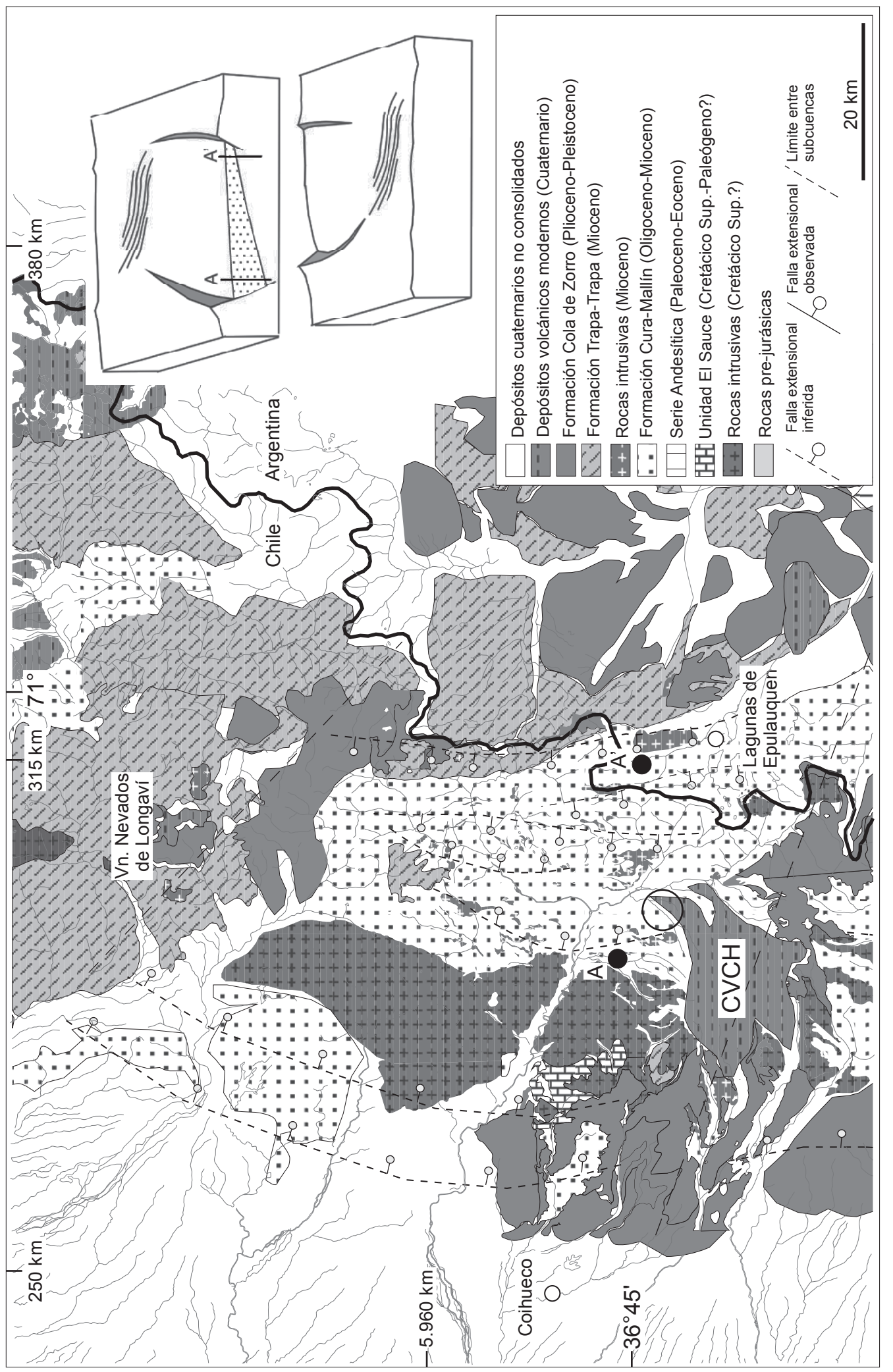

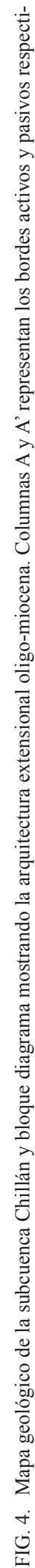


sedimentario volcanoclástico denominado miembro Malla Malla. Este está compuesto por areniscas, conglomerados y lutitas, con menor participación de tobas, brechas, calizas y niveles carbonosos, asociados a un ambiente fluvial y lacustre somero. Originalmente Muñoz y Niemeyer (1984) consideraron el miembro Malla Malla más joven que el miembro Río Queuco, sin embargo, más al sur, Suárez y Emparan (1997) y Burns (2002) demostraron que ambas facies son contemporáneas y que se interdigitan. La presencia de depósitos lacustres localizados hacia el borde occidental de la subcuenca es de vital importancia para el entendimiento tectono-estratigráfico de los sistemas de 'rift'. Estas rocas requieren un exceso de espacio de acomodación en relación a la tasa de sedimentación y habitualmente se las correlaciona con las zonas que han experimentado mayor subsidencia dentro de las cuencas, es decir, sus bordes activos (Lambiase, 1990).

El relleno de la subcuenca Chillán registra una disminución del espesor en dirección hacia el este, desde el punto máximo localizado sobre el borde activo hasta llegar al borde pasivo en donde se desarrolla el mínimo. En este último punto está representado por una secuencia de rocas volcánicas pertenecientes a la Formación Epulauquen, correlacionada con la Formación Cura-Mallín, y compuestas por lavas, tobas, areniscas y aglomerados volcánicos con un espesor total aproximado de $1.000 \mathrm{~m}$ (Pesce, 1981; Zanettini, 1987) (Fig. 5).

Las estructuras compresivas de inversión que se desarrollaron con posterioridad al evento extensional (que se describen más adelante), presentan una notable coincidencia espacial con los bordes tectónicos inferidos para la subcuenca Chillán. Específicamente, la familia de estructuras de escala mayor se concentra sobre el propuesto borde activo, lo que sumado a las características propias del relleno (presencia de depósitos lacustres y desarrollo del máximo espesor en columna) ha sido utilizado como base para inferir el sistema de falla que conformaba dicho borde activo, así como también para el resto de las subcuencas del sistema de cuencas de Cura-Mallín.
A

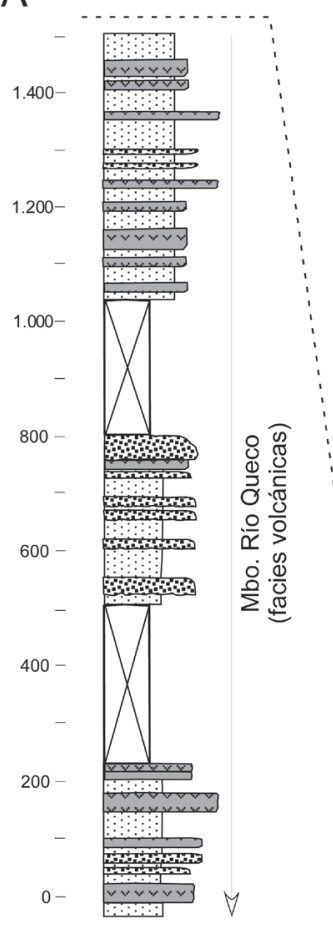

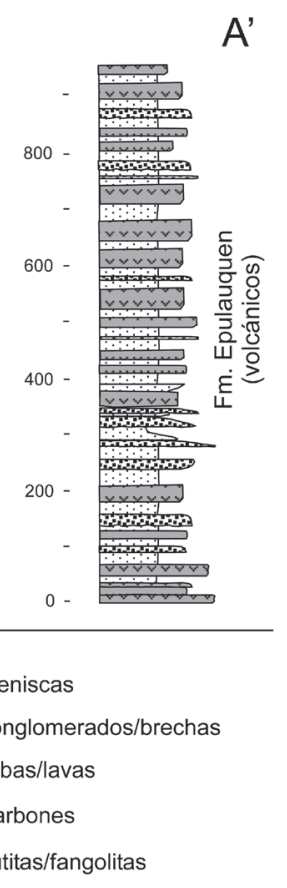

Subcuenca Chillán

FIG. 5. Estratigrafía de relleno de la subcuenca Chillán en cada uno de los bordes, para su localización ver figura 4. Columna A (borde activo) modificada de Muñoz y Niemeyer (1984), columna A’ (borde pasivo) modificada de Pesce (1981). 
El intervalo de tiempo representado por el relleno de esta subcuenca corresponde al Mioceno Temprano y ha sido determinado en base a relaciones estratigráficas y a dataciones radiométricas. Sobre el borde activo se tiene una datación por método $\mathrm{K}$-Ar en tobas del miembro volcánico Río Queco de la Formación Cura-Mallín, que entregó un valor de $19 \pm 0,46 \mathrm{Ma}$ (roca total, IIG/MMAJ, 1979), mientras que la formación Trapa Trapa que la sobreyace ha sido asignada al intervalo $11,8 \pm 2,1-18,6 \pm 1,0$ Ma por medio de dataciones del mismo método realizadas en una lava andesítica (plagioclasa y roca total respectivamente, Muñoz y Niemeyer, 1984).

\subsubsection{Subcuenca Lileo}

La subcuenca Lileo se encuentra limitada al norte por el Complejo Volcánico Nevados de Chillán (CVCh) y al sur por el Complejo Volcánico Copahue Callaqui (CVCC). Presenta una orientación NS con dimensiones aproximadas de $120 \mathrm{~km}$ de largo y $75 \mathrm{~km}$ de ancho. Su arquitectura extensional está caracterizada por un hemigraben de polaridad este que alterna con lo observado en la subcuenca de Chillán inmediatamente al norte. Su borde activo está localizado en las nacientes del río Lileo en territorio argentino, mientras que el borde pasivo se encuentra en el sector de Trupán-Antuco en territorio chileno (Fig. 6).

Sobre el borde activo el relleno de la subcuenca está caracterizado por un espesor total de $2.750 \mathrm{~m}$ ( $\sin$ base reconocida) de rocas volcánicas y volcanoclásticas de la Formación Cura-Mallín (Gutiérrez y Miniti, 1985)², en donde Burns (2002) identificó dos facies principales de acuerdo con la cercanía de centros volcánicos, una proximal y otra distal (Fig. 7). La facies proximal volcánica consiste en brechas volcanoclásticas asociadas a depósitos de flujos de detritos y en forma subordinada a depósitos de calizas y fangolitas lacustres, y a flujos de lava y depósitos piroclásticos. La facies distal volcanoclástica comprende principalmente el retrabajo de material volcánico piroclástico, el cual está representado por areniscas y lutitas, asociadas a ambientes fluviales y lacustres.

En el borde pasivo Niemeyer y Muñoz (1983) documentaron alrededor de 900-1.500 m (sin base reconocida) de rocas volcánicas y volcanoclásticas pertenecientes a la Formación Cura-Mallín, lo que ha permitido reconocer una disminución en el espesor del relleno de la subcuenca, esta vez desde el este hacia el oeste (Fig. 7). El relleno de la subcuenca en este punto está caracterizado por dos miembros, uno inferior denominado Río Queuco y uno superior denominado Malla Malla. El miembro basal está compuesto por tobas, algunas intercalaciones de areniscas y conglomerados y en forma subordinada por lavas andesíticas. Por su parte, el miembro superior está compuesto por areniscas, conglomerados, fangolitas y subordinadamente algunos horizontes carbonosos. Carpinelli (2000) interpretó estas rocas como facies depositadas en ambientes fluviales y aluviales tanto proximales como distales, los cuales fueron utilizados como posibles indicadores de proximidad a los bordes tectónicos de la cuenca extensional.

Al igual que en la subcuenca Chillán, los bordes de esta subcuenca no han sido reconocidos en terreno, siendo inferidos a partir de las mismas características observadas más al norte. Además de la coincidencia espacial entre dichos bordes con los depósitos lacustres, el máximo espesor del relleno y las estructuras de inversión de mayor escala, Jordan et al. (2001) reconoció en una línea sísmica una falla extensional de manteo al oeste con más de $1.000 \mathrm{~m}$ de desplazamiento que fue interpretada como la falla maestra del borde activo de la subcuenca Lileo en las nacientes del río del mismo nombre.

El lapso de tiempo asociado al relleno de esta subcuenca abarca el intervalo Oligoceno Tardío-Mioceno Temprano, el cual ha sido determinado por medio de dataciones radiométricas. Sobre el borde activo de la subcuenca en territorio argentino se tienen dataciones realizadas en tobas de la Formación Cura-Mallín por método ${ }^{40} \mathrm{Ar} /{ }^{39} \mathrm{Ar}$ (hornblenda) que entregan un rango de edad que abarca 24,6 $\pm 1,8-22,8 \pm 0,7 \mathrm{Ma}$ (Jordan $e t$ al., 2001; Burns, 2002). Además, sobre el borde pasivo en territorio chileno existen dataciones realizadas en rocas volcánicas de la Formación Cura-Mallín por método ${ }^{40} \mathrm{Ar} /{ }^{39} \mathrm{Ar}$ y K-Ar que han permitido asignar un intervalo de edad comprendido entre 19,8 $\pm 0,4$ (Herriott, 2006; Herrirot et al., 2006; Wertheim et

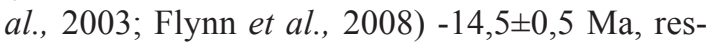
pectivamente (plagioclasa en fragmento volcánico, Niemeyer y Muñoz, 1983). Por otra parte, dataciones radiométricas por método K-Ar realizadas en rocas de la formación Trapa-Trapa en territorio chileno, han permitido asignar un rango de edad que abarca entre los 18,2 $\pm 0,8-14,7 \pm 0,7 \mathrm{Ma}$ (plagioclasa en material

Gutiérrez, A; Minniti, S. 1985. Comisión Geológica N 1. Reconocimiento Geológico de las Nacientes del río Lileo. YPF informe (inédito), Departamento de Minas. Provincia del Neuquén: 24 p. 


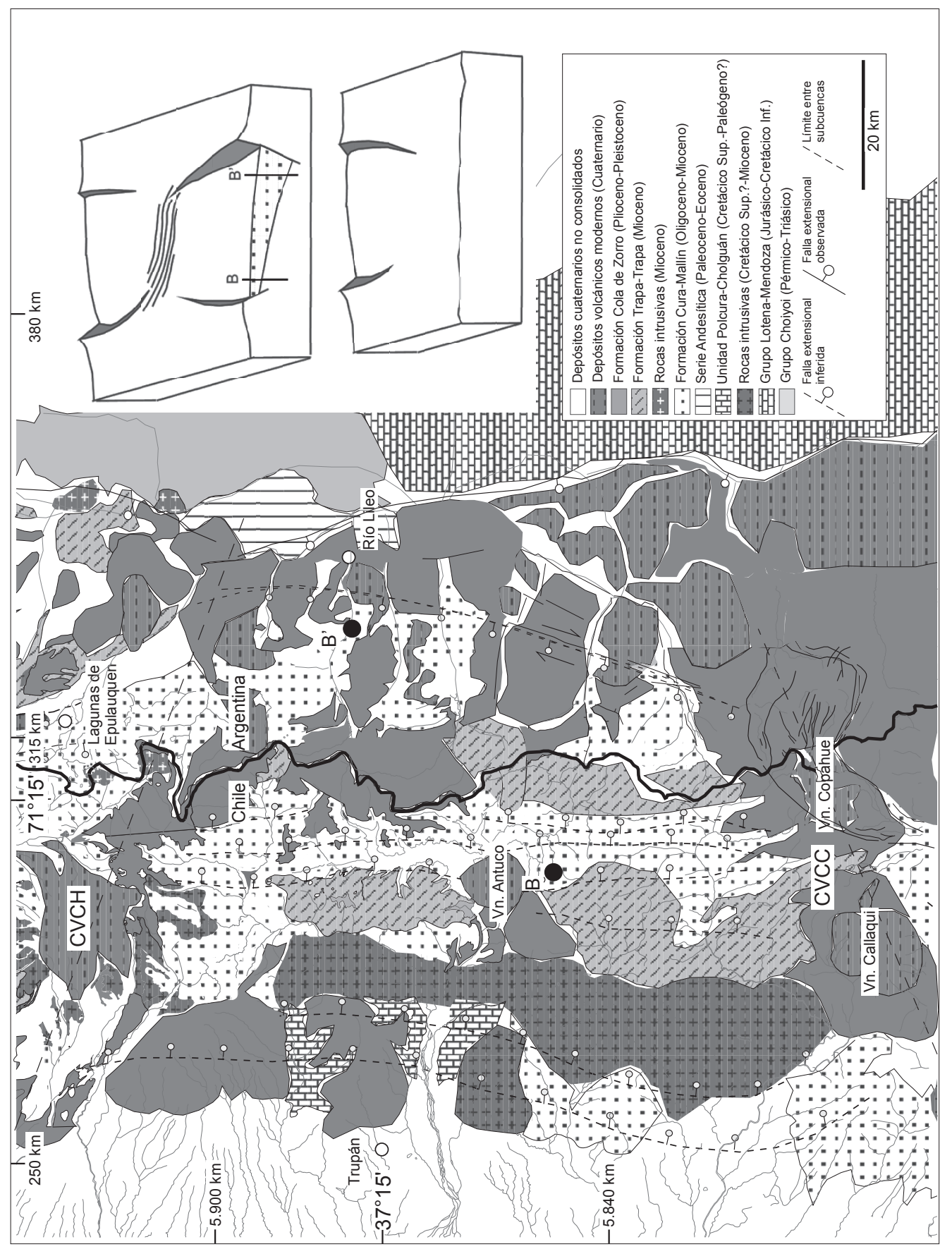




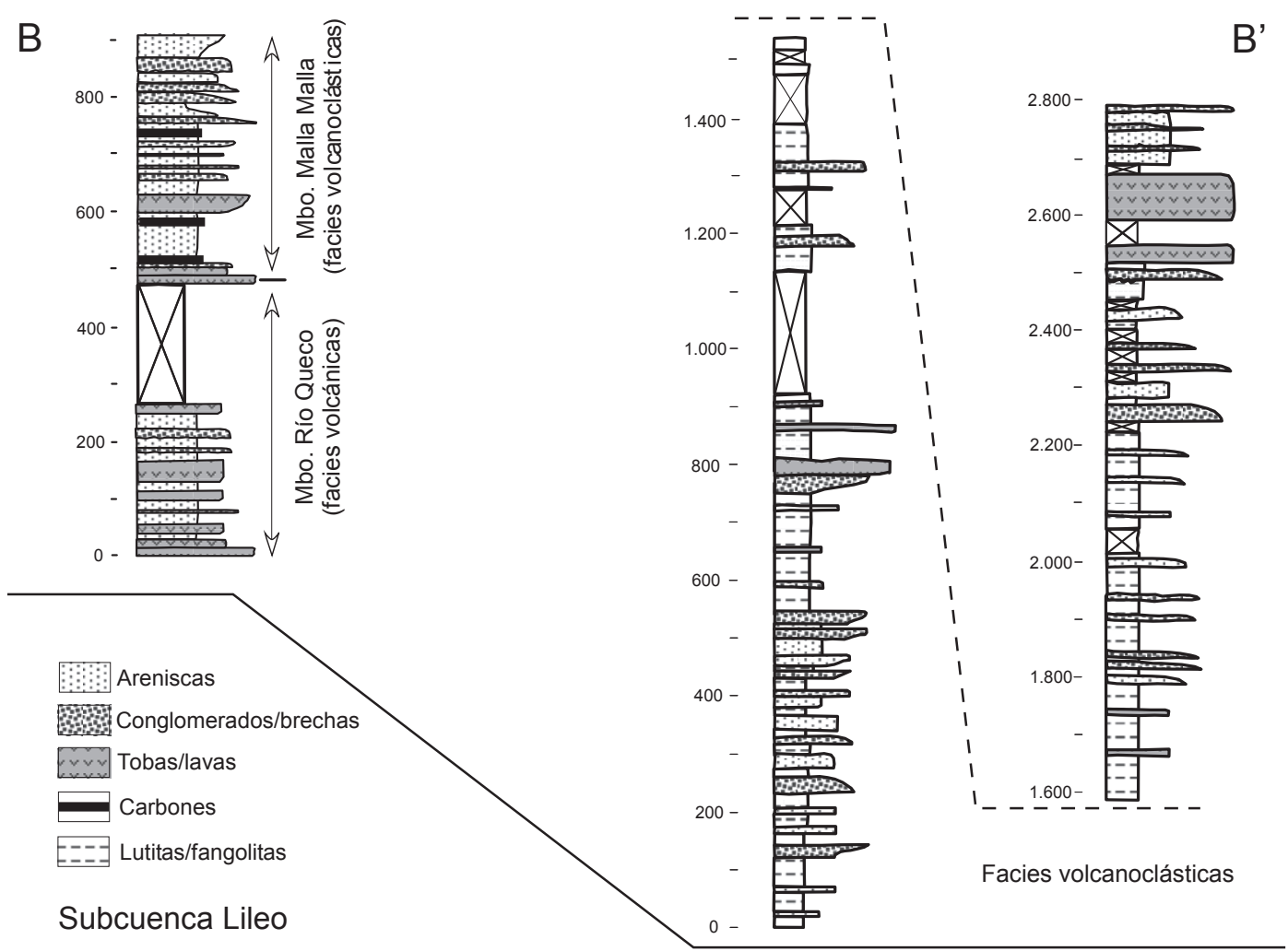

FIG. 7. Estratigrafía de relleno de la subcuenca Lileo en cada uno de los bordes; ver figura 6 para su localización. Columna B (borde pasivo) modificada de Niemeyer y Muñoz (1984) y Carpinelli (2000), columna B' (borde activo) modificada de Gutiérrez y Minitti (1985).

clástico no especificado, Niemeyer y Muñoz, 1983), mientras que en Argentina dataciones por método ${ }^{40} \mathrm{Ar} /{ }^{39} \mathrm{Ar}$ (hornblenda en andesita) han entregado un valor de 16,2 $\pm 0,2 \mathrm{Ma}$ (Jordan et al., 2001). Dada la semejanza de edad entre las formaciones CuraMallín y Trapa Trapa, existe la posibilidad de una interdigitación entre ambas.

\subsubsection{Subcuenca Lonquimay}

La subcuenca Lonquimay se extiende entre el Complejo Volcánico Copahue-Callaqui (CVCC) por el norte y el volcán Sollipulli por el sur. Se orienta principalmente en dirección NNE y presenta un largo de $120 \mathrm{~km}$ y un ancho inferido de $80 \mathrm{~km}$, debido a que su límite oriental se encuentra totalmente cubierto por depósitos volcánicos cuaternarios. La dimensión del ancho de la subcuenca de Lonquimay fue estimada mediante la comparación con las dos subcuencas de más al norte y por la ubicación de los primeros afloramientos de rocas mesozoicas de la Cordillera del Viento por el este. Su arquitectura extensional nuevamente alterna respecto de la subcuenca inmediatamente al norte, estando caracterizada esta vez por un hemigraben de polaridad al oeste. El borde activo se encuentra localizado en las cercanías de Lonquimay en territorio chileno y su borde pasivo debiera estar en territorio argentino en las cercanías de Las Lajas, coincidiendo con el borde oriental de la fosa de Loncopué (Fig. 8).

El relleno de la subcuenca Lonquimay en su borde activo está caracterizado por un espesor aproximado de $2.600 \mathrm{~m}$ de rocas volcánicas y volcanoclásticas de la Formación Cura-Mallín. Suárez y Emparan (1997) reconocieron dos miembros principales, uno volcánico denominado Guapitrío y otro sedimentario volcanoclástico denominado Río Pedregoso. El segundo sobreyace y engrana con el primero pudiendo incluso estar intercalado localmente. El miembro inferior está constituido por una secuencia volcánica principalmente piroclástica compuesta por tobas 


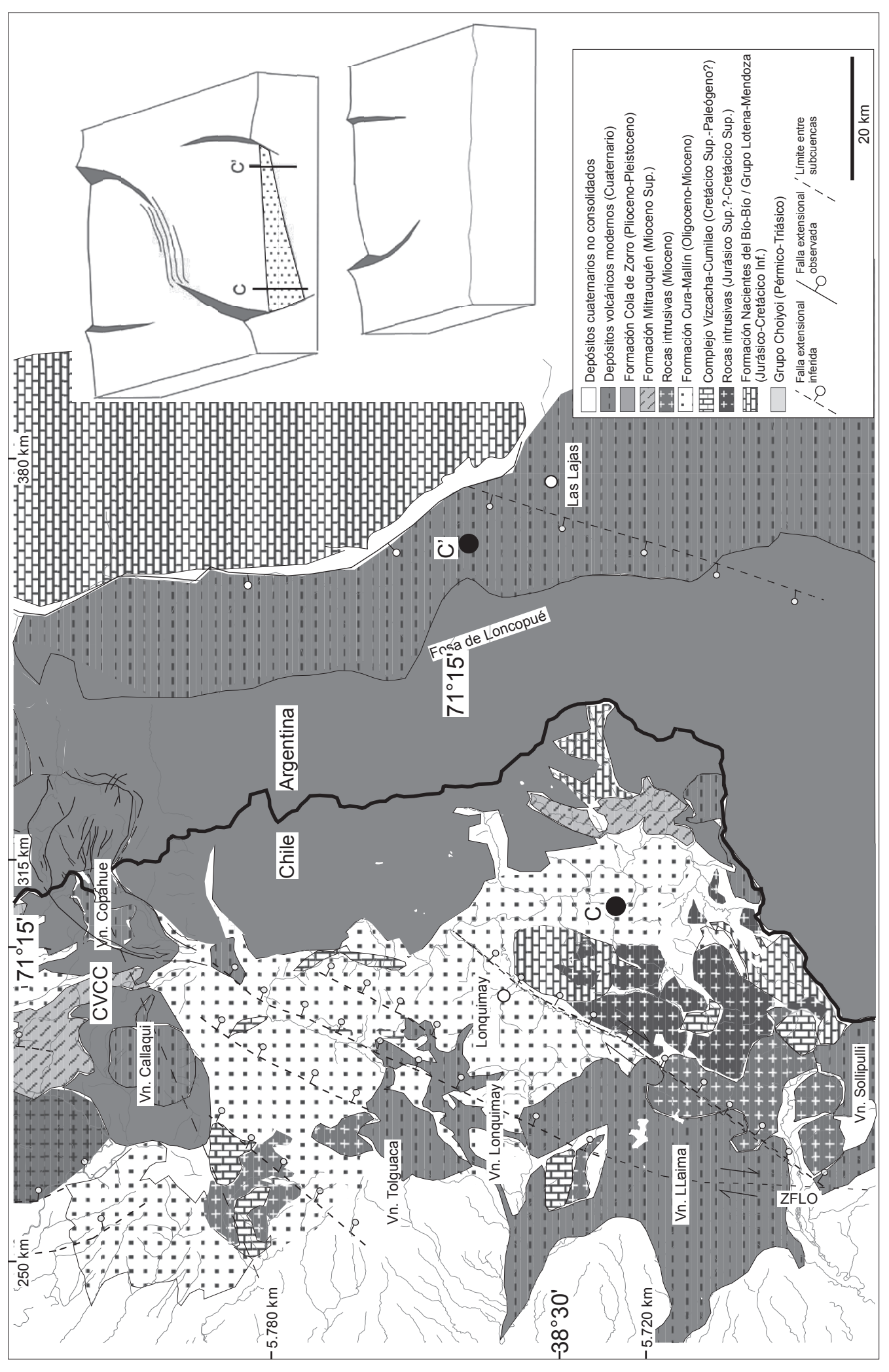


C

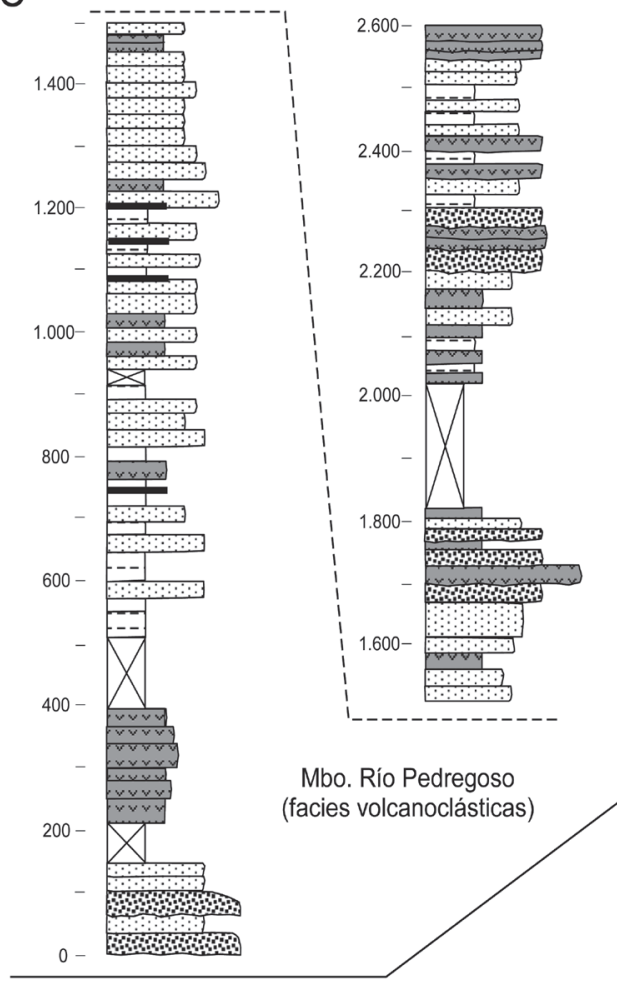

C'

Sin afloramientos

Areniscas

32. Conglomerados/brechas

ivive Tobas/lavas

Carbones

:---- Lutitas/fangolitas

Subcuenca Lonquimay

FIG. 9. Estratigrafía de relleno de la subcuenca Lonquimay en su borde activo; ver figura 8 para su localización. Columna C tomada de Carpinelli (2000).

con intercalaciones de lavas y capas sedimentarias continentales. A su vez, el miembro superior está compuesto por lutitas, fangolitas areniscas, calizas y algunos horizontes carbonosos, asociados a facies lacustres, deltaicas y fluviales (Fig. 9). Dentro de la facies sedimentaria volcanoclástica del miembro Río Pedregoso, en cercanías de Lonquimay se han reconocido una serie de estructuras de 'slumping', interpretadas como zonas tectónicamente activas que evidencian la cercanía de los límites de la subcuenca (Suárez y Emparan, 1995; Carpinelli, 2000). Por otra parte, en el trabajo de Cisternas y Díaz (1985) se interpretó una evolución de facies para los depósitos sedimentarios que evolucionan desde fluvial, pasando por lacustre, deltaico y terminando con abanicos aluviales, la cual es una característica típica reconocida en el registro sedimentario de cuencas de 'rift' continentales (Lambiase, 1990).

Nuevamente, en forma similar a lo que ocurre en las otras dos subcuencas del norte, el borde activo de la cuenca Lonquimay tampoco ha sido reconocido en superficie. Este ha sido inferido siguiendo el mismo razonamiento y argumentos utilizados para las otras dos subcuencas anteriormente descritas.

El relleno de la subcuenca Lonquimay abarca el intervalo de tiempo Mioceno Temprano-Medio, el cual ha sido determinado a partir de dataciones radiométricas. Para el sector del borde activo de la cuenca (único aflorante) se han obtenido dataciones por método $\mathrm{K}-\mathrm{Ar}$ en lavas andesíticas que entregan edades entre 19,9 $\pm 1,4$ (roca total)-10,7 $\pm 1,1 \mathrm{Ma}$ (plagioclasa) respectivamente (Suárez y Emparan, 1997). Sobreyaciendo en concordancia a la Formación Cura-Mallín se encuentran los depósitos volcánicos de la Formación Mitrauquén. Estos corresponden a depósitos ignimbríticos, secuencias de lavas, aglomerados volcánicos y conglomerados fluviales que han sido asignados al Mioceno Tardío en base a dataciones radiométricas por método $\mathrm{K}-\mathrm{Ar}$, con un rango de edad entre 9,5 2,8 (biotita en toba)- $8,0 \pm 0,3$ $\mathrm{Ma}$ (roca total en andesita) respectivamente (Suárez y Emparan, 1997). 


\subsection{Zonas de acomodación estructural}

Las subcuencas de Chillán, Lileo y Lonquimay se caracterizan por presentar una polaridad alternante, es decir, que cada unidad extensional tiene su sector de máxima subsidencia sobre bordes opuestos, característica geométrica que hace necesario la presencia de al menos dos zonas de acomodación estructural. Dichas estructuras, aunque no tienen representación en superficie, son un elemento estructural fundamental que permiten el balance de la deformación entre subcuencas adyacentes y habrían constituido altos topográficos que separaban a las subcuencas de Chillán, Lileo y Lonquimay. Las dos zonas de acomodación han sido denominadas informalmente para este trabajo como Zona de Acomodación Chillán (ZACH) y Zona de Acomodación Copahue-Callaqui (ZACC) (Fig. 10). Observaciones de terreno han permitido documentar una disminución progresiva del espesor de la Formación Cura-Mallín a medida que se acerca hacia la ZACH (Radic, 2006). Dicho acuñamiento se ha observado tanto desde el norte (subcuenca Chillán) como del sur (subcuenca Lileo), para llegar a desaparecer completamente bajo el volcán Chillán, en donde se puede observar el contacto directo de las rocas volcánicas cuaternarias con las rocas intrusivas del Batolito de Santa Gertrudis (Muñoz y Niemeyer, 1984). No ha sido posible reconocer evidencias que permitan relacionar dicho acuñamiento con alzamiento y erosión, por lo que ha sido interpretado en el presente trabajo como producto del paleorrelieve existente entre ambas subcuencas adyacentes. En las nacientes del río de las Minas, en el alto del río Nuble sobre el extremo suroriental de la subcuenca Chillán, es posible encontrar una sección reducida de la Formación Cura-Mallín (400 m), compuesta en su parte basal por una toba brechosa que incluye clastos angulosos de rocas intrusivas idénticas a las del Batolito de Santa Gertrudis (ubicación en Fig. 4). No existe claridad en cuanto a la edad de este batolito, el cual originalmente fue asignado al Mioceno Tardío por medio de una serie de dataciones radiométricas $\mathrm{K}-\mathrm{Ar}$ (biotita y roca total) que entregaban un rango de edad 5,8 $\pm 0,3-17,2 \pm 0,88 \mathrm{Ma}$ (Muñoz y Niemeyer, 1984); sin embargo, las relaciones de contacto con la sobreyaciente Formación Cura-Mallín conforma la primera evidencia para postular una edad más antigua en concordancia con dataciones (K-Ar en biotita) reportadas sobre el límite suroccidental del batolito con un rango 83,9 $9 \pm 3,8-85,4 \pm 5,2 \mathrm{Ma}$ (IIG/ MMAJ, 1979'; Gajardo, 1981).

De forma similar, se ha observado en terreno una disminución del espesor de la Formación Cura-Mallín en los alrededores de la ZACC. En la porción sur de la subcuenca de Lileo y sobre el flanco NO del volcán Callaqui es posible observar los depósitos volcánicos modernos directamente apoyados por sobre rocas ígneas del Intrusivo de la Cordillera Andina (Ferraris, 1981). Asimismo para la parte norte de la subcuenca Lonquimay y sobre el flanco SO del volcán Callaqui, es posible reconocer los depósitos volcánicos pliocénicos directamente apoyados por sobre rocas del Complejo Vizcacha-Cumilao de edad cretácica superior-paleógena (Suárez y Emparan, 1997).

\section{Inversión tectónica miocena superior}

El evento compresivo del Mioceno Tardío que afectó a la Cordillera de los Andes en la zona de estudio produjo que las cuencas desarrolladas con anterioridad fueran invertidas tectónicamente entre los 10 y 8 Ma (Suárez y Emparan, 1995; Jordan et al., 2001; Burns, 2002; Folguera et al., 2006b; Radic et al., 2002; Melnick et al., 2006b), exhumando y deformando las rocas que conformaban sus rellenos. El estilo de deformación es típico de faja plegada de piel gruesa con basamento involucrado y está caracterizada por una geometría doble vergente reconocida en muchas cuencas invertidas alrededor del mundo (McClay, 1995). A continuación se describe la estructura particular para cada subcuenca.

\subsection{Subcuenca Chillán}

$\mathrm{La}$ arquitectura de los depósitos que rellenan la subcuenca Chillán están caracterizados por una serie de pliegues anticlinales y sinclinales de orientación general N-S, subparalelos y que se encuentran restringidas exclusivamente al dominio interno de ésta (limitados por los bordes tectónicos E-O inferidos y sin traspasar las zonas de acomodación estructural en dirección N-S). Las estructuras presentan un cambio de rumbo hacia el SE en la porción más sur de la subcuenca justo en las cercanías del Complejo Volcánico Nevados de Chillán (CVCh) (Fig.11).

En sección está representada por una geometría doble vergente con dos familias de estructuras de escalas distintas. La familia de estructuras mayores se ubica directamente por sobre la porción 

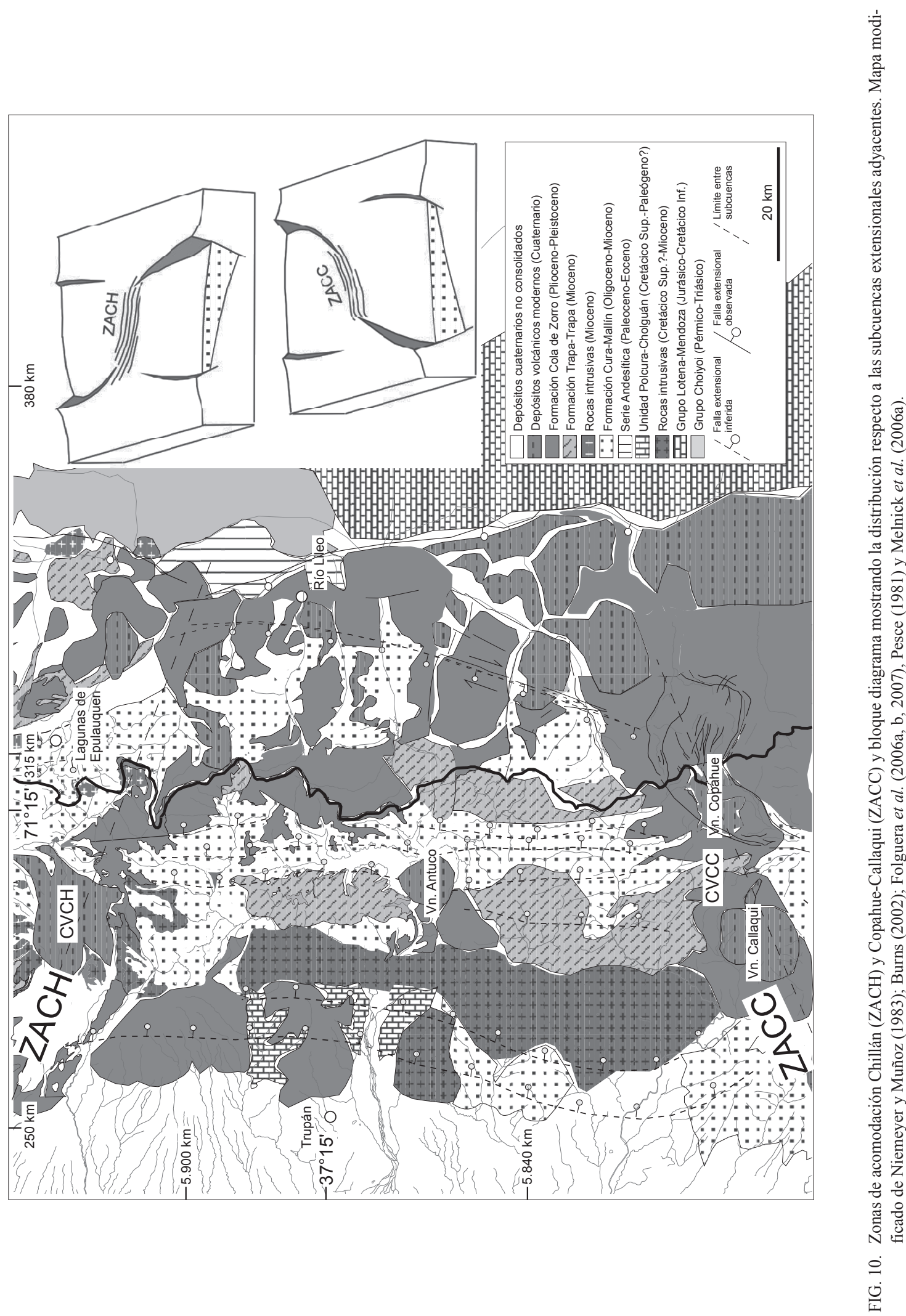


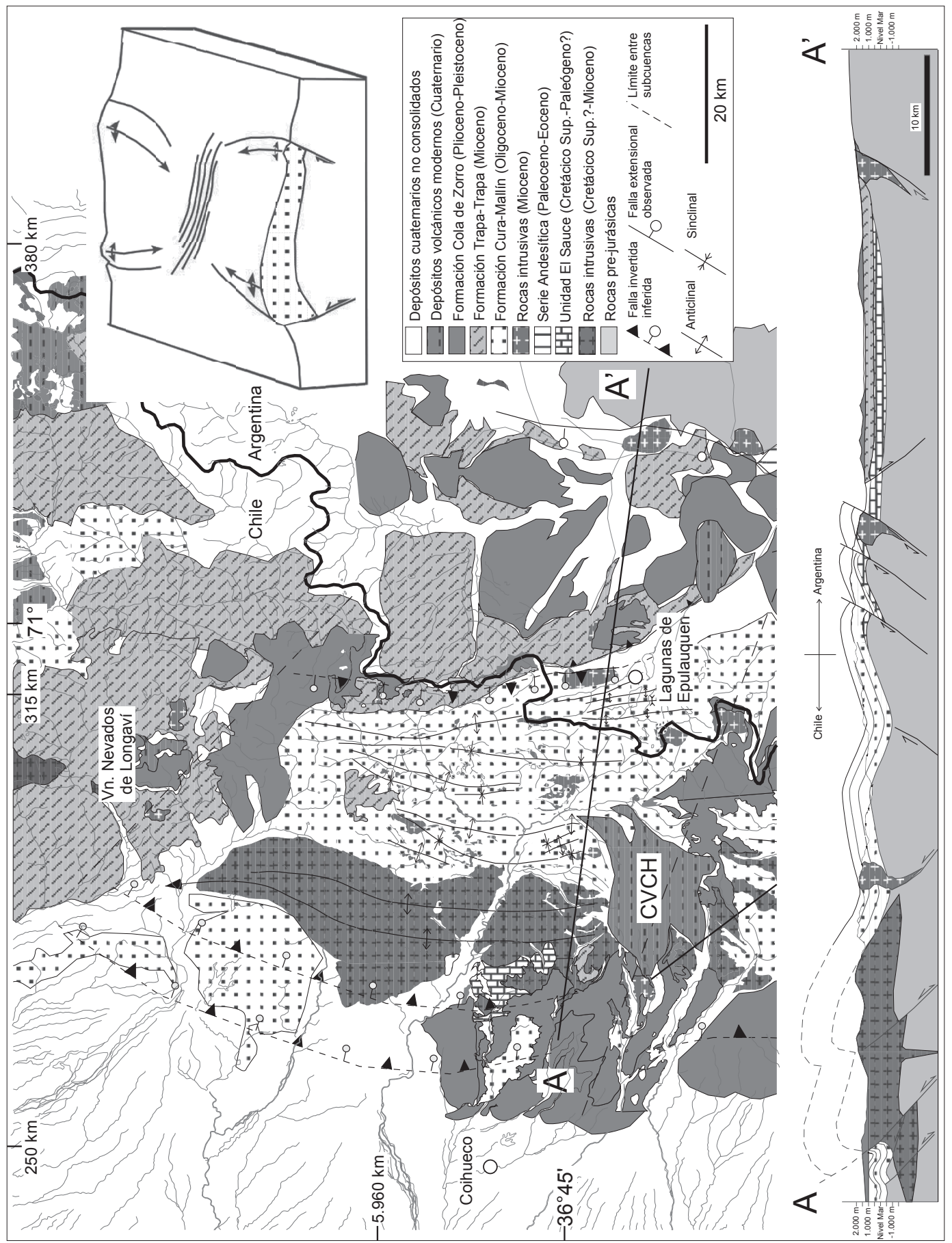

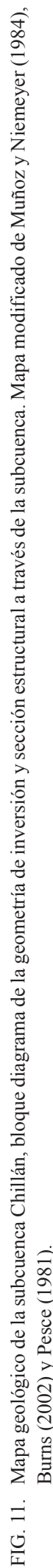


occidental de la subcuenca, coincidiendo con el antiguo sector de máxima subsidencia extensional. Estas corresponden a anticlinales por propagación de falla, con vergencia al oeste y que habrían sido generados como producto de la reutilización de las fallas originalmente extensionales que conformaban el borde activo inferido de la subcuenca de Chillán. La dimensión de dichas estructuras alcanza del orden de los $10 \mathrm{~km}$ de longitud de onda y de 60-70 km de largo. Por su parte, la familia de estructuras de menor escala se localiza hacia la porción oriental de la subcuenca, coincidiendo con el antiguo borde pasivo inferido. Estas a su vez se caracterizan por anticlinales por propagación de falla, subparalelos, de vergencia al este y con dimensiones de $3-5 \mathrm{~km}$ de longitud de onda y de 40-50 km de largo (Fig. 11).

Como es habitual en terrenos invertidos, la exhumación y deformación es más intensa hacia los bordes de la cuenca, en donde generalmente afloran en superficie las rocas más antiguas del relleno, e incluso hasta las rocas que conforman el basamento. Para el caso del borde activo de la subcuenca Chillán, afloran rocas ígneas correspondientes al Batolito de Santa Gertrudis; sin embargo, como se detalló anteriormente, no hay claridad respecto a su edad. En concordancia con el hallazgo de la brecha basal reconocida en el sector del río de las Minas, se tiene además que la distribución areal del Batolito de Santa Gertrudis se caracteriza por una franja orientada N-S, y totalmente rodeada por afloramientos de la Formación Cura-Mallín que presentan manteos opuestos y buzamiento bidireccional. Esta característica geométrica permite interpretar estas rocas ígneas como el núcleo de un gran anticlinal desarrollado en rocas de la Formación Cura-Mallín, las cuales habrían sido erosionadas en las cercanías del borde activo de la subcuenca Chillán, permitiendo así el afloramiento de su núcleo de basamento. Esto corresponde a la segunda evidencia que permite plantear la hipótesis de una edad más antigua para el Batolito de Santa Gertrudis, o para parte de él.

Las fallas extensionales que conformaban los bordes de la subcuenca Chillán y que posteriormente fueron invertidas no han sido reconocidas tampoco en superficie, sin embargo, los numerosos pliegues compresivos presentes permiten inferir dichas fallas. Estas se encontrarían en las cercanías de la localidad de Coihueco en territorio nacional y en la localidad de las Lagunas de Epulauquen en territorio argentino (Fig. 11).

\subsection{Subcuenca Lileo}

La arquitectura de la subcuenca Lileo está representada por una serie de pliegues anticlinales y sinclinales de orientación general N-S, subparalelos, y que se encuentran restringidos exclusivamente al dominio interno de esta (limitados por los bordes tectónicos E-O inferidos y sin traspasar las zonas de acomodación estructural en dirección N-S). Al igual que la subcuenca anterior, las estructuras presentan un cambio de rumbo hacia el SE en la porción más sur del depocentro, justo en las cercanías del CVCh (Fig. 12).

La estructura en sección está representada por una geometría doble vergente con dos familias de estructuras de escala distintas, una mayor localizada en la porción oriental de la subcuenca y otra menor ubicada en la porción occidental de ella. La familia de estructuras mayores es coincidente con el antiguo borde activo extensional inferido y se caracteriza por anticlinales de propagación de falla, asimétricos, de vergencia oriental, y que habrían sido formados por la inversión de las antiguas fallas extensionales que limitaban el depocentro por el este. La dimensión de estas estructuras alcanza del orden de los $10 \mathrm{~km}$ de longitud de onda y de 70-80 km de largo. Asimismo, se tienen las estructuras menores coincidiendo con el antiguo borde pasivo inferido de la subcuenca, las cuales se caracterizan por anticlinales por propagación de falla, de vergencia al oeste y con dimensiones de 3-5 $\mathrm{km}$ de longitud de onda y de $60-80 \mathrm{~km}$ de largo (Fig. 12).

En el sector oriental de la subcuenca Lileo y en coincidencia con la familia de estructuras mayores, se ha reconocido el afloramiento de rocas de la porción inferior de la Formación Cura-Mallín y además rocas de la Serie Andesítica que conforman parte del basamento. Esto nuevamente apunta a la coincidencia espacial del borde activo de la subcuenca con una intensa deformación y exhumación del relleno sedimentario de la cuenca extensional. Por otra parte, sobre el borde occidental de la subcuenca, aflora un extenso batolito conocido como Intrusivo de la Cordillera Andina y que presenta características composicionales similares al de Santa Gertrudis inmediatamente al norte. Se dispone de solo dos dataciones radiométricas K-Ar (roca total) en la porción oriental, las cuales entregan un rango 55,34 $\pm 1,88-76,5 \pm 1,83 \mathrm{Ma}$ (Ferraris, 1981). En cuanto a su distribución areal, se observa que estas rocas 


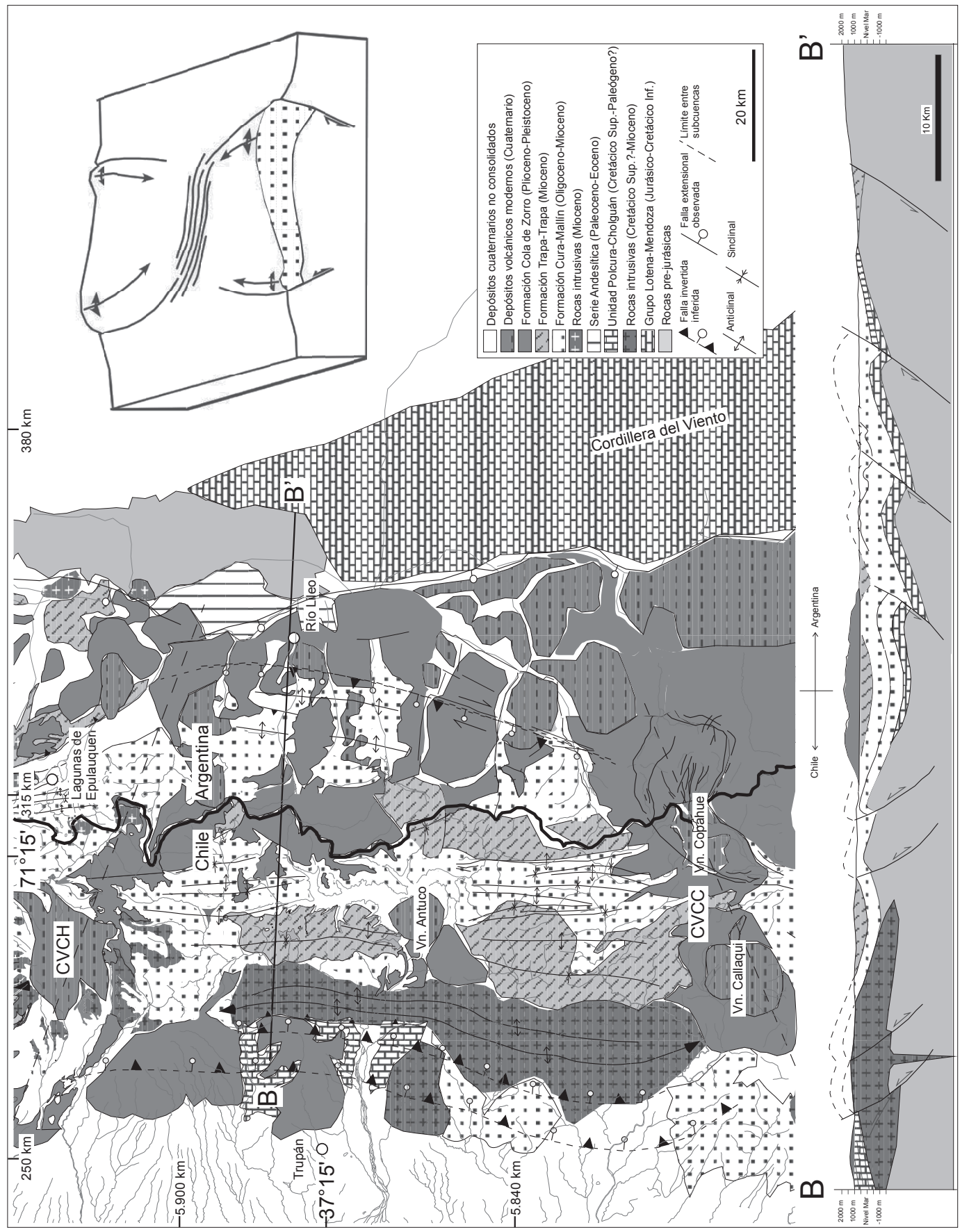

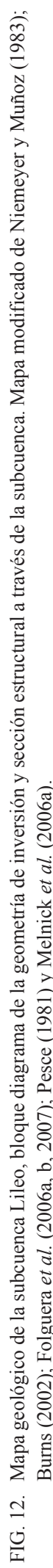


también se encuentran rodeadas por afloramientos de la Formación Cura-Mallín con manteos opuestos y buzamiento bidireccional, conformando el núcleo de un gran anticlinal. Por lo tanto, en forma similar a lo observado para la subcuenca inmediatamente al norte, lo descrito anteriormente constituye una evidencia más que sustenta la hipótesis de una edad más antigua que miocena para estas rocas ígneas.

$\mathrm{Al}$ igual que en la subcuenca Chillán, no ha sido posible reconocer en superficie las fallas extensionales de borde de cuenca que fueron invertidas. Éstas nuevamente han sido inferidas a partir de los pliegues compresivos reconocidos en terreno y se encontrarían en la localidad de Trupán en Chile y río Lileo en Argentina (Fig. 12).

\subsection{Subcuenca Lonquimay}

La arquitectura de la subcuenca Lonquimay está caracterizada por una serie de pliegues anticlinales y sinclinales de orientación general NNE, subparalelos, y que se encuentran restringidos exclusivamente a su borde occidental, ya que hacia territorio argentino todo se encuentra cubierto por depósitos volcánicos plio-pleistocénicos (Fig. 13). En la sección está representada por una familia de pliegues anticlinales y sinclinales de propagación de falla, vergentes al oeste y que se habrían formado por la reactivación de las antiguas fallas extensionales inferidas que limitaban esta subcuenca por el oeste. La dimensión de las estructuras alcanza del orden de los $10 \mathrm{~km}$ de longitud de onda y de $70 \mathrm{~km}$ de largo y se encuentran dispuestas en echelón. En el sector afloran rocas jurásicas y cretácicas que forman parte del basamento de la subcuenca Lonquimay, como la Formación Nacientes del Bío-Bío, Grupo Plutónico Gualletué y Complejo Vizcacha-Cumilao (Suárez y Emparan, 1997), las que se encuentran incluidas en la deformación y están conformando los núcleos de los anticlinales al igual que lo observado en las otras subcuencas de más al norte. Nuevamente se puede observar la coincidencia entre la intensa deformación y exhumación, con el borde activo de la antigua cuenca extensional.

Los depósitos volcánicos plio-holoceno de la Fosa de Loncopué han cubierto completamente la mitad oriental de la subcuenca Lonquimay, escondiendo el borde pasivo. Sin embargo, de acuerdo con lo observado en el resto de las subcuencas, este debiera estar estructurado en forma similar al resto de los bordes pasivos y preservado bajo la cobertura volcánica, tal como lo propusieran Folguera et al. (2003) y García y Folguera (2005).

Una vez más, las fallas extensionales invertidas han sido interpretadas en el presente trabajo en forma indirecta a partir de los pliegues descritos en superficie y se localizan en las cercanías de Lonquimay. Estas mismas fallas han sido reconocidas en los trabajos de Melnick et al. (2006b) y de Potent (2003), los cuales las han caracterizado como fallas transcurrentes de edad pliocena-holocena formando parte de la terminación norte del sistema de falla de Liquiñe Ofqui.

\section{Volcanismo y deformación Plioceno-Holoceno}

Los depósitos volcánicos del Plioceno-Holoceno se han dividido en el presente trabajo en dos unidades mayores, una de edad plio-pleistocénica inferior y otra pleistocena superior-holocena. La unidad plio-pleistocénica inferior está representada por una extensa secuencia volcánica que se distribuye en la región limítrofe chileno-argentina de la zona de estudio. Incluye varias estructuras volcánicas y rocas asociadas, principalmente basaltos y andesitas, relacionadas con estratovolcanes muy erosionados y que constituyen extensas mesetas subhorizontales que fosilizan la estructura de las rocas subyacentes. En Chile esta unidad se conoce como Formación Cola de Zorro (González y Vergara, 1962) y asociación volcánica de la precordillera oriental (Suárez y Emparan, 1997), mientras que hacia Argentina se le conoce como Formación Quebrada Honda (Pesce, 1981), abarcando un rango de edad aproximado entre 5 y 1 Ma (Suárez y Emparan, 1997; Folguera et al., 2006b; García y Folguera, 2005).

La unidad pleistocena superior-holocena está representada en Argentina por una secuencia de productos volcánicos emitidos a partir de centenares de centros monogénicos que cubren el retroarco interno, los cuales se distribuyen espacialmente sobre el límite oriental de la Fosa de Loncopué, cubriendo en parte las rocas volcánicas previas (García y Folguera, 2005). En territorio chileno esta unidad está representada por el arco volcánico actual, que está formado por los volcanes cuaternarios Antuco, Lonquimay y Lanín y los complejos volcánicos Nevados de Chillán (CVCh) y Copahue-Callaqui (CVCC).

El Complejo Volcánico Nevados de Chillán (CVCh) corresponde a un sistema estratovolcánico 


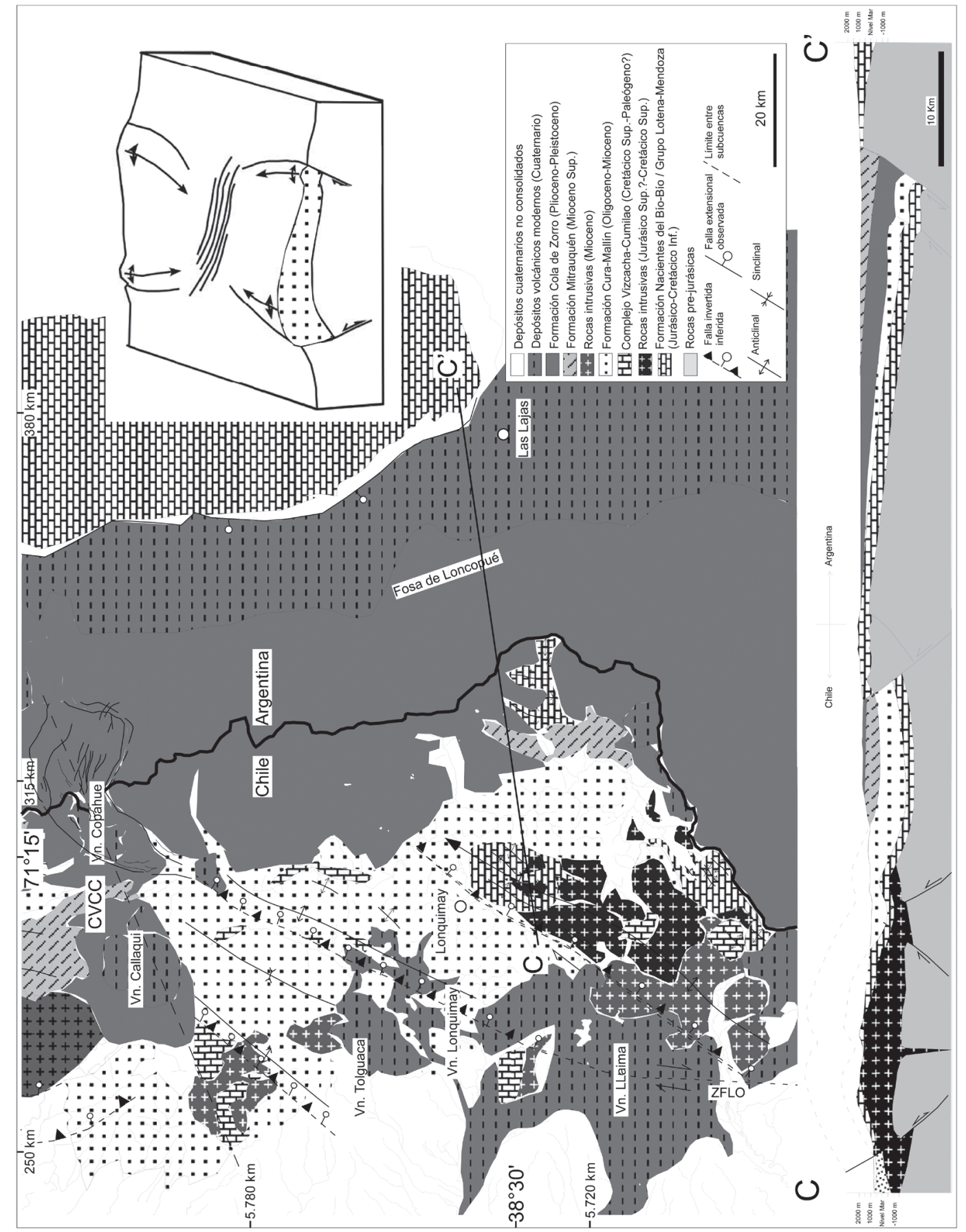




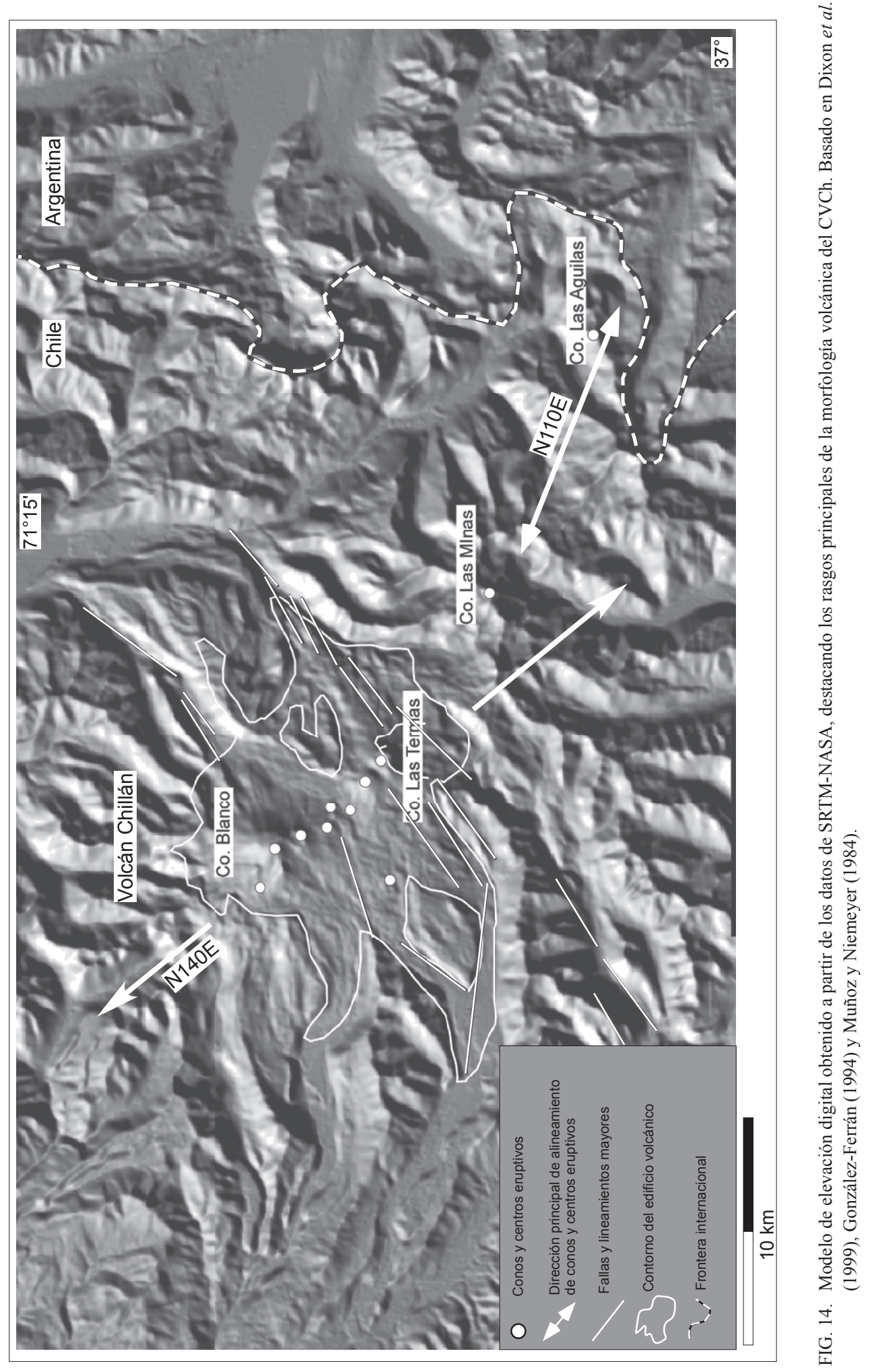


representado por dos centros de emisión, separados aproximadamente por $6 \mathrm{~km}$ y alineado con una serie de conos y cráteres secundarios en dirección aproximada N140E (Dixon et al., 1999; González-Ferrán, 1994). Además, se ha reconocido también dirección de alineamiento N110E para los depósitos volcánicos y paleocentros de emisión de la Formación Cola de Zorro, definiendo así el rumbo general de este antiguo estratovolcán profundamente erosionado (Muñoz y Niemeyer, 1984) (Fig. 14).

El CVCC está caracterizado por un sistema volcánico compuesto por dos volcanes, el Callaqui y el Copahue. El Callaqui corresponde a un estratovolcán fisural elongado en dirección N60E, que presenta un alineamiento de conos parásitos y piroclásticos en la misma dirección (Moreno y Lahsen,1986; GonzálezFerrán, 1994). El Copahue está representado por un estratovolcán de morfología elongada y orientada en dirección N50-60E, en forma paralela a una serie de cráteres y conos secundarios (Naranjo y Polanco, 2004; Melnick et al., 2006a; González-Ferrán, 1994). Los depósitos volcánicos pliocénicos por sobre los cuales se edificó el Volcán Copahue, se encuentran afectados por una gigantesca caldera de cráter semielíptico, que se orienta aproximadamente N80E (Fig. 15).

En conjunto, el volcanismo plioceno-holoceno ha sido interpretado como producto de un régimen tectónico extensional que habría afectado la Cordillera Principal en el retroarco y un régimen transtensional que la habría afectado en el intraarco durante los últimos 5 Ma (Folguera et al., 2000, 2002, 2003, 2006b; García y Folguera, 2005; Ramos y Folguera, 2005; Melnick et al., 2006b, c). Sin embargo, en la zona de estudio existe una situación bastante particular que corresponde a la superposición espacial entre los complejos volcánicos cuaternarios $\mathrm{CVCh}$ y CVCC, los depósitos y estructuras volcánicas de la unidad Plioceno-Pleistoceno Inferior y estructuras mayores heredadas de las cuencas extensionales del Oligoceno-Mioceno, estas son las zonas de acomodación estructural ZACH y ZACC.

\section{Discusión y conclusiones}

El estudio integrado de las cuencas cenozoicas en la zona de trabajo ha permitido caracterizar la estructura mayor del sistema de 'rift' de Cura-Mallín. Se han reconocido al menos tres subcuencas independientes separadas por dos zonas de acomodación estructural, en donde en cada uno de los depocentros se puede observar las características clásicas reconocidas en otras cuencas del mundo, como lo son sus dimensiones, asimetría y alternancia en la polaridad (Rosendhal, 1987; Morley et al., 1990). Además, al interior de las subcuencas también es posible observar las características propias del relleno, como las variaciones en el espesor, la distribución de las facies sedimentarias y la columna estratigráfica típica de 'rift' continental (Lambiase, 1990).

Los límites tectónicos de cada una de las subcuencas (borde activo y pasivo) no han sido reconocidos hasta ahora en superficie, por lo que fueron interpretados en forma indirecta a partir de las características geométricas propias de cada depocentro. Utilizando los datos de la geometría del relleno, asimetría y localización de máximo espesor, característica y distribución de estructuras de inversión y polaridad estructural y relevo de subcuencas contiguas, las fallas o sistemas de fallas que conformaban los límites de cada subcuenca fueron inferidas basándose en la coexistencia espacial entre las zonas que experimentaron una máxima subsidencia en el período extensional, con las zonas en donde se reconocen las estructuras de inversión de mayor escala, y por ende, las que sufrieron un mayor alzamiento y erosión durante el período de inversión tectónica. Las zonas de acomodación estructural representan un elemento geométrico necesario para la mecánica de la deformación extensional. La orientación de cada una de estas ha sido inferida a partir de las terminaciones en planta de las estructuras de inversión, sus direcciones de relevo y la curvatura asintótica insinuada en las cercanías de dos subcuencas contiguas (Figs. 11, 12, 13). De acuerdo con lo anterior, la $\mathrm{ZACH}$ tendría un rumbo aproximado N110E y la ZACC de N60E, lo que sumado a la característica de alto topográfico de intracuenca para el oligo-mioceno permite clasificarlas como zonas de acomodación estructural 'opuestas sin traslape' según Rosendahl (1987).

La orientación inferida para las zonas de acomodación también ha sido corroborada por medio de la distribución y morfología del volcanismo de los complejos Nevados de Chillán y CallaquiCopahue. Para el CVCh se ha observado que su morfología general, centros de emisión y también los paleocentros asociados a la Formación Cola de Zorro, se orientan en una dirección N110-140E (Dixon et al., 1999; Muñoz y Niemeyer, 1984), en 


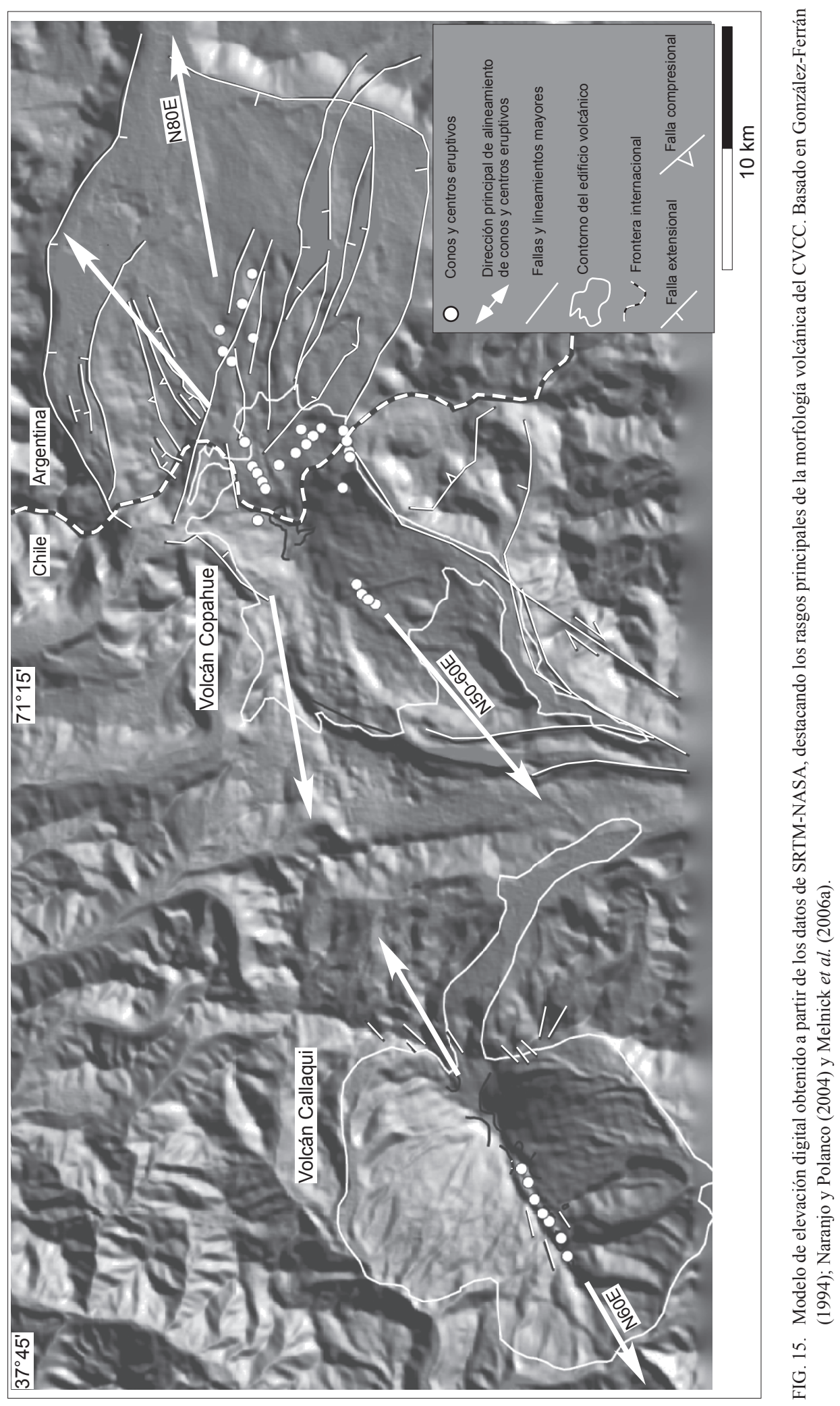


forma subparalela a la dirección propuesta para la $\mathrm{ZACH}$ inmediatamente por debajo (Fig. 16). Esta orientación, subperpendicular a la dirección de máximo esfuerzo regional actual ( $\sigma 1, \mathrm{NNE}-\mathrm{SSO}$ ) (Lavenu y Cembrano, 1999), no es en principio favorable para el ascenso magmático (Nakamura, 1977); sin embargo, tal como ha sido propuesto por Tibaldi (1995) y Acocella et al. (2002), y reconocido también por Cembrano y Moreno (1994), López-Escobar et al. (1995), y Lara et al. (2004), estructuras heredadas podrían conformar zonas de debilidad y actuar como alimentadoras del sistema. La zona de acomodación ZACH inmediatamente por debajo del CVCh, habría constituido esta zona de debilidad permitiendo y facilitando el ascenso, emplazamiento y desarrollo del magmatismo y volcanismo plioceno-holoceno.

El CVCC se caracteriza por una morfología general de sus aparatos volcánicos y centros de emisión alineados en dirección N50-60E (Niemeyer y Muñoz, 1983; Melnick et al., 2006a), coincidiendo con la orientación inferida para la ZACC, como ya lo habían postulado Folguera et al. (2003) (Fig. 14). La presencia de la ZACC como zona de debilidad, sumado a su orientación subparalela a la dirección de máximo esfuerzo regional actual $(\sigma 1)$ hacen de esta zona en particular un lugar que presenta características especialmente favorables para el emplazamiento magmático y desarrollo volcánico, el cual está evidenciado por el extenso alineamiento de los volcanes Callaqui, Copahue, Caldera del Agrio y Cordillera de Mandolegue (Folguera et al., 2006b; Melnick et al., 2006a) (Fig. 16).

La inversión tectónica durante el evento compresivo del Mioceno Tardío se tradujo en la reutilización de las fallas originalmente extensionales que formaban parte de la cuenca de Cura-Mallín, exhumando y deformando los depósitos asociados. No ha sido posible encontrar evidencias que permitan dilucidar si es que las zonas de acomodación también habrían sido afectadas por dicha deformación. La arquitectura resultante se caracteriza por dos familias de pliegues y fallas de orientación subparalela, que presentaría una coincidencia espacial con los antiguos límites extensionales de cada una de las subcuencas. La familia de estructuras de mayor escala se encuentra coincidiendo con los bordes activos de cada una de las subcuencas, mientras que la familia de menor escala lo hace con respecto a los bordes pasivos. También es posible observar una alternancia de las familias de estructuras mayores, de un borde al otro, para cada subcuenca adyacente, evidenciando nuevamente la coincidencia entre dichas estructuras de inversión y la asimetría propia de las cuencas extensionales heredadas. Esta es una característica habitual en terrenos invertidos, en donde la estructura compresiva sobreimpuesta sigue preservando las características originales de las cuencas extensionales (McClay, 1995).

En sección, la arquitectura de la cuenca de CuraMallín está representada por una geometría doble vergente en donde también se puede observar una coincidencia entre las zonas más alzadas y deformadas actualmente, con las zonas que en el pasado constituían las partes más bajas y que habrían generado el máximo espacio de acomodo al interior de la subcuenca.

Basado en las observaciones de campo, se plantea la hipótesis de que parte de los intrusivos mayores en la zona de estudio (Batolito de Santa Gertrudis e Intrusivos de la Cordillera Andina) puedan corresponder a rocas más antiguas, emplazadas con anterioridad al desarrollo del sistema extensional de Cura-Mallín, e incluidas en la deformación del evento de inversión tectónica del Mioceno Tardío.

El frente orogénico actual se localiza en el retroarco al norte de los $38^{\circ} \mathrm{S}$ y está caracterizado por una tectónica transcurrente dextral con presencia local de transtensión y transpresión, mientras que al sur de dicha latitud se traslada al intraarco, en donde está representado por una tectónica transcurrente dextral con desarrollo local solo de transtensión (Lavenu y Cembrano, 1999; Melnick et al., 2006b, c; Folguera et al., 2003, 2004). El traspaso de la deformación del frente orogénico ocurre exactamente por sobre el CVCC $\left(38^{\circ} \mathrm{S}\right)$ en el centro de la zona de estudio, en donde la deformación cuaternaria habría utilizado la antigua estructura del ZACC 'favorablememente orientada' (subparalela a la dirección del máximo esfuerzo horizontal 'Shmax', Lavenu y Cembrano, 1999) para ser reactivada en sentido transcurrente dextral, induciendo el desarrollo del 'pull-apart' de la Caldera del Agrio (Fig. 16) (Melnick et al., 2006a, c; Folguera et al., 2004; 2006b). Por el contrario, la ZACH que no se encontraba sobre el frente orogénico y además orientándose en forma subperpendicular a la dirección de Shmax (Lavenu y Cembrano, 1999), fue afectada por una deformación transcurrente caracterizada por un sistema de fallas locales sobrepuestos a dicha estructura como producto del estado de estrés regional (Radic, 2006). 


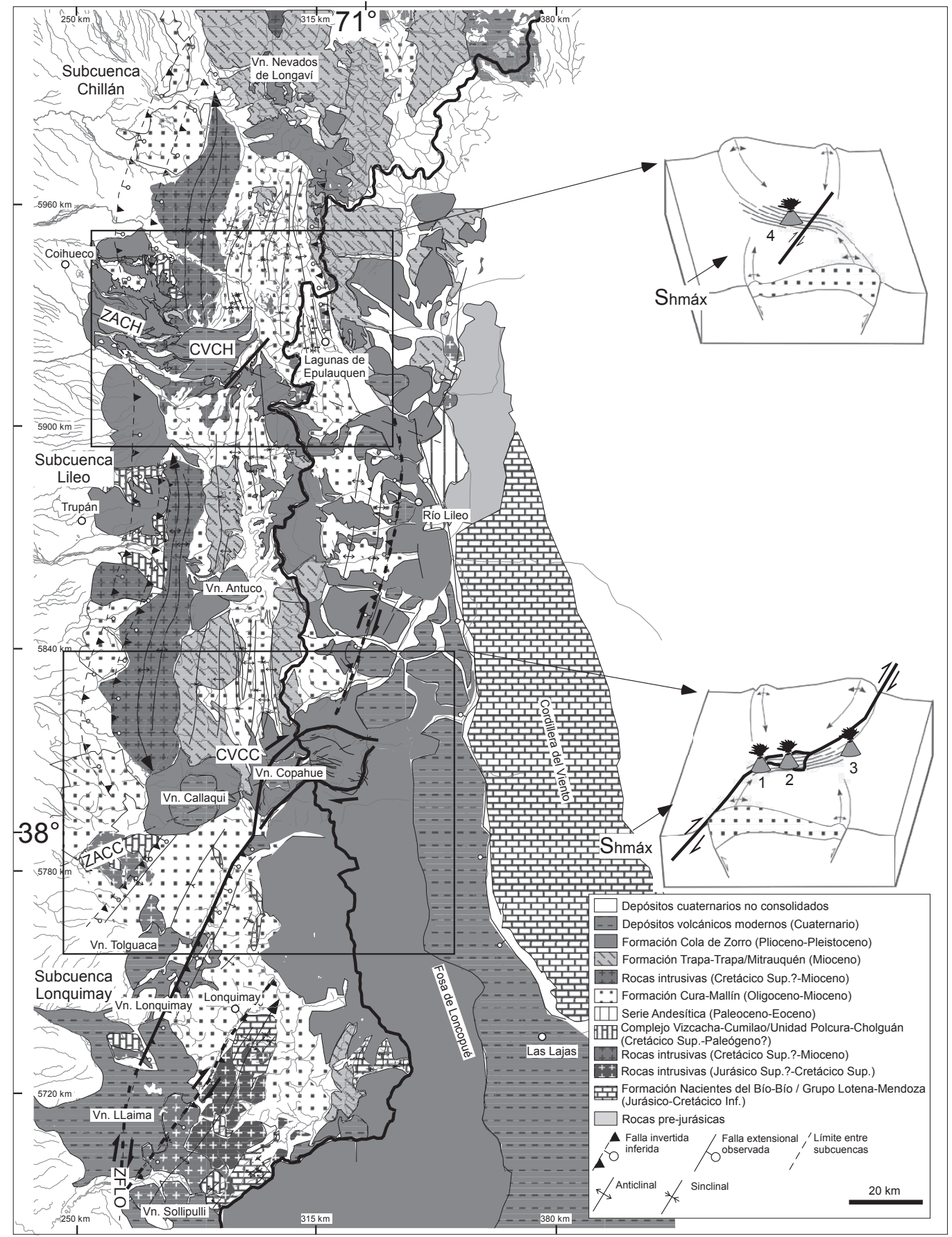

FIG. 16. Mapa geológico de la zona de estudio destacando la neotectónica general y bloques diagrama ilustrando la relación entre el basamento, volcanismo cuaternario y neotectónica. Dirección Shmáx tomada de Lavenu y Cembrano (1999). ZLFO: Zona de falla Liquiñe-Ofqui; CVCH: Complejo volcánico Nevados de Chillán; CVCC: Complejo volcánico Copahue-Callaqui; ZACH: Zona de acomodación Chillán; ZACC: Zona de acomodación Copahue-Callaqui. 1. Volcán Callaqui; 2. Volcán Copahue; 3. Volcán Tolón-Cordillera de Mandolegue; 4. Volcán Chillán. Mapa modificado de Muñoz y Niemeyer (1984); Niemeyer y Muñoz (1983); Súarez y Emparan (1997); Burns (2002); Pesce (1981); Folguera et al. (2006a, b, 2007) y Melnick et al. (2006a). 
Algunos de los elementos estructurales mayores propios de las cuencas extensionales cenozoicas que conforman el basamento en la zona de estudio, pueden constituir zonas de debilidad que controlen y faciliten la migración y ascenso del magmatismo y volcanismo plioceno-holoceno. Por esto, el análisis sistemático de cuencas como método de trabajo, puede ser utilizado como una herramienta para el estudio de la relación genética entre volcanismo y basamento, así como también la recurrencia tectónica en la evolución geológica de los Andes chilenos.

\section{Agradecimientos}

La presente contribución se enmarca dentro de una serie de trabajos de exploración de hidrocarburos realizados por ENAP-SIPETROL durante los últimos años en Chile. Quisiera agradecer a la empresa por la posibilidad de realizar y publicar este trabajo y al invaluable aporte de las distintas personas que participaron en el trabajo de campo y entendimiento del problema. En especial mis agradecimientos a R. Fuenzalida, A. Carpinelli, L. Rojas, E. Zurita y J. Ríos. Finalmente, el autor agradece la minuciosa revisión y valiosas sugerencias por parte de los editores, T. Jordan, V. Ramos, J. Cembrano y L. Lara.

\section{Referencias}

Acocella, V.; Salvini, F.; Funiciello, R.; Faccenna, C. 1999. The role of transfer structures on volcanic activity at Campi Flegrei (Southern Italy). Journal of Volcanology and Geothermal Research 91: 123-139.

Acocella, V.; Korme, T.; Salvini, F.; Funiciello, R. 2002. Elliptic calderas in the Ethiopian Rift: control of pre-existing structures. Journal of Volcanology and Geothermal Research 119: 189-203.

Burns, W.M. 2002. Tectonics of the Southern Andes from stratigraphic, thermochronologic, and geochemical perspectives. Ph.D. Thesis (Unpublished), Cornell University: $218 \mathrm{p}$.

Burns, W.M.; Jordan, T.E.; Copeland, P.; Kelley, S.A. 2006. The case for extensional tectonics in the OligoceneMiocene Southern Andes as recorded in the Cura-Mallín basin ( $\left.36^{\circ}-38^{\circ} \mathrm{S}\right)$. In Evolution of an Andean margin: A tectonic and magmatic view from the Andes to the Neuquén Basin ( $35^{\circ}-39^{\circ} \mathrm{S}$ lat.) (Kay, S.; Ramos, V.; editors). Geological Society of America, Special Paper 407: 163-184. Doi:10.1130/206.2407(08).

Carpinelli, A. 2000. Análisis estratigráfico, paleoambiental, estructural y modelo tectono-estratigráfico de la Cuenca Cura-Mallín VIII y IX Región, Chile. Memoria de Título
(Inédito), Universidad de Concepción, Departamento de Ciencias de la Tierra: 158 p.

Cembrano, J.; Moreno, H. 1994. Geometría y naturaleza contrastante del volcanismo cuaternario entre los $38^{\circ} \mathrm{S}$ y $46^{\circ} \mathrm{S}$ : Dominios compresionales y tensionales en un régimen transcurrente? In Congreso Geológico Chileno, No. 7, Actas 1: 240-244. Concepción.

Charrier, R.; Pinto, L.; Rodríguez, M.P. 2007. Tectonostratigraphic evolution of the Andean Orogen in Chile. In The Geology of Chile (Moreno, T.; Gibbons, W.; editors). The Geological Society of London, Special Publication: 21-116.

Cisternas, M.E.; Díaz, L. 1985. Los depósitos terciarios lacustres de Lonquimay, Chile. Zentralblatt für Geologie und Paläentologie 1 (9-10): 1351-1362.

Cobbold, P.; Rossello, E. 2003. Aptian to recent compressional deformation, foothills of the Neuquén Basin, Argentina. Marine and Petroleum Geology 20: 429-443.

Cobbold, P.; Rossello, E.; Marques, F. 2008. Where is the evidence for Oligocene rifting in the Andes? Is it in the Loncopué Basin of Argentina? In International Symposium on Andean Geodynamics, No. 7, extended abstracts: 148-151. Nice, France.

De la Cruz, R.; Suárez, M. 1997. El Jurásico de la cuenca de Neuquén en Lonquimay, Chile: Formación Nacientes del Biobío (38-39² S). Revista Geológica de Chile 24 (1): 3-24.

Dixon, H.; Murphy, M.; Sparks, S.; Chávez, R.; Naranjo, J.; Dinkley, P.; Young, S.; Gilbert, J.; Pringle, M. 1999. The geology of Nevados de Chillán volcano, Chile. Revista Geológica de Chile 26 (2): 227-253.

Ferraris, F. 1981. Hoja de Los Angeles-Angol, Región del Bío-Bío. Instituto de Investigaciones Geológicas, Mapas Geológicos Preliminares 5: 26 p., escala 1:250.000.

Flynn, J.; Charrier, R.; Croft, D.; Gans, P.; Herriott, T.; Wertheim, J.; Wyss, A. 2008. Chronologic implications of new Miocene mammals from the Cura-Mallín and Trapa-Trapa formations, Laguna del Laja area, south central Chile. Journal of South American Earth Sciences 26: 412-423.

Folguera, A.; Ramos, V.A. 2000. Control estructural del volcán Copahue $\left(38^{\circ} \mathrm{S}-71^{\circ} \mathrm{O}\right)$ : implicancias tectónicas para el arco volcánico. Revista de la Asociación Geológica Argentina 55: 229-244.

Folguera, A.; Ramos, V.A.; Melnick, D. 2002. Partición de la deformación en la zona del arco volcánico de la cordillera neuquina en los últimos 30 millones de años $\left(36^{\circ}-39^{\circ} \mathrm{S}\right)$. Revista Geológica de Chile 29 (2): 227-240. 
Folguera, A.; Ramos, V.A.; Melnick, D. 2003. Recurrencia en el desarrollo de cuencas de intraarco. Cordillera Neuquina (37³0’S). Revista de la Asociación Geológica Argentina 58 (1): 3-19.

Folguera, A.; Ramos, V.A.; Hermanns, R.; Naranjo, J. 2004. Neotectonics in the foothills of the southernmost Central Andes $\left(37^{\circ}-38^{\circ} \mathrm{S}\right)$ : Evidence of strike-slip displacement along the Añatir-Copahue fault zone. Tectonics 23, TC5008. doi: 10.1029/2003T C001533.

Folguera, A.; Ramos, V.A.; González Díaz, E.F.; Hermanns, R. 2006a. Miocene to Quaternary deformation of the Guañacos fold-and-thrust-belt in the Neuquén Andes between $37^{\circ}$ and $37^{\circ} 30^{\prime}$ S. In Evolution of an Andean margin: A tectonic and magmatic view from the Andes to the Neuquén Basin $\left(35^{\circ}-39^{\circ} \mathrm{S}\right.$ lat) (Kay, S.; Ramos, V.; editors). Geological Society of America, Special Paper 407: 247-266. doi:10.1130/206.2407(11).

Folguera, A.; Zapata, T.; Ramos, V.A. 2006b. Late Cenozoic extension and the evolution of the Neuquén Andes. In Evolution of an Andean margin: A tectonic and magmatic view from the Andes to the Neuquén Basin ( $35^{\circ}-39^{\circ} \mathrm{S}$ lat.) (Kay, S.; Ramos, V.; editors). Geological Society of America, Special Paper 407: 267-285, doi:10.1130/206.2407(12).

Folguera, A.; Ramos, V.A.; Zapata, T.; Spagnuolo, M. 2007. Andean evolution at the Guañacos and Chos Malal Fold and Thrust Belt $\left(36^{\circ} 30^{\prime}-37^{\circ} \mathrm{S}\right)$. Journal of Geodynamics 44: 129-148.

Gajardo, A. 1981. Hoja de Concepción-Chillán, Región del Bío-Bío. Instituto de Investigaciones Geológicas, Mapas Geológicos Preliminares 4: 32 p., escala 1:250.000.

García, E.; Folguera, A. 2005. El Alto de Copahue-Pino Hachado y la Fosa de Loncopué: un comportamiento tectónico episódico, Andes neuquinos $\left(37^{\circ}-39^{\circ} \mathrm{S}\right)$. Revista Geológica Argentina 60 (4): 742-761.

González, O.; Vergara, M. 1962. Reconocimiento geológico de la Cordillera de los Andes entre los paralelos $35^{\circ}$ y $38^{\circ}$ latitud sur. Universidad de Chile, Instituto de Geología, Publicación 24: 119 p.

González-Ferrán, O. 1994. Volcanes de Chile. Instituto Geográfico Militar: $640 \mathrm{p}$.

Groeber, P. 1956. La Serie Andesítica patagónica. Sus relaciones, posición y edad. Revista de la Asociación Geológica Argentina 9: 39-42.

Herriott, T. 2006. Stratigraphy, structure and ${ }^{40} \mathrm{Ar} /{ }^{39} \mathrm{Ar}$ geochronology of the southeastern Laguna del Laja area: Implications for the mid-late Cenozoic evolution of the Andes near $37.5^{\circ} \mathrm{S}$, Chile. M.Sc. Thesis (Unpublished), University of California: 109 p.
Herriott, T.M.; Charrier, R.; Croft, D.A.; Flynn, J.J.; Gans, P.B.; Wertheim, J.A.; Wyss, A.R. 2006. Geologic mapping, sedimentology, structure, and $\mathrm{Ar} / \mathrm{Ar}$ geochronology of the southeast Laguna del Laja area, Central Andes, Chile ( $\left.37^{\circ} 30^{\prime} \mathrm{S} 71^{\circ} 15^{\prime} \mathrm{W}\right)$. Geological Society of America, Abstracts with programs, Special Meetings 2: 66-67.

Jordan, T.; Burns, M.; Veiga, R.; Pángaro, F.; Copeland, P.; Kelley, S.; Mpodozis, C. 2001. Extension and basin formation in the southern Andes caused by increased convergence rate: A mid-Cenozoic trigger for the Andes. Tectonics 20 (3): 308-324.

Lambiase, J. 1990. A Model for Tectonic Control of Lacustrine Stratigraphic Sequences in Continental Rifts Basins. In Lacustrine Basin Exploration -case studies and modern analogs (Katz, B.J.: editor). American Association of Petroleum Geologists, Memoir 50: 265-276.

Lara, L.; Moreno, H.; Naranjo, J. 2004. Rhyodacitic fissure eruption in Southern Andes (Cordón Caulle; $40.5^{\circ} \mathrm{S}$ ) after the 1960 (Mw:9.5) Chilean earthquake: a structural interpretation. Journal of Volcanology and Geothermal Research 138: 127-138.

Lavenu, A.; Cembrano, J. 1999a. Compressional and transpressional-stress pattern for Pliocene and Quaternary brittle deformation in forearc and intra-arc zones (Andes of Central and Southern Chile). Journal of Structural Geology 21: 669-1691.

Lavenu, A.; Cembrano, J. 1999b. Estados de esfuerzo compresivo plioceno y compresivo-transpresivo pleistoceno, Andes del sur, Chile (38-42 $30^{\circ}$ 'S). Revista Geológica de Chile 26 (1): 67-87.

López-Escobar, L.; Cembrano, J.; Moreno, H. 1995. Geochemistry and tectonics of the Chilean Southern Andes basaltic Quaternary volcanism $\left(37^{\circ}-46^{\circ} \mathrm{S}\right)$. Revista Geológica de Chile 22 (2): 219-234.

McClay, K.R. 1995. The geometries and kinematics of inverted fault systems: a review of analogue models studies. Geological Society, Special Publication 88: 97-118.

Melnick, D.; Folguera, A.; Ramos, V. 2006a. Structural control on arc volcanism: The Caviahue-Copahue complex, Central to Patagonian Andes transition $\left(38^{\circ} \mathrm{S}\right)$. Journal of South American Earth Science 22: 66-88.

Melnick, D.; Rosenau, M.; Folguera, A.; Echtler, H. 2006b. Neogene tectonic evolution of the Neuquén Andes western flank $\left(37^{\circ}-39^{\circ} \mathrm{S}\right)$. In Evolution of an Andean margin: A tectonic and magmatic view from the Andes to the Neuquén Basin $\left(35^{\circ}-39^{\circ} \mathrm{S}\right.$ lat) (Kay S.; Ramos V.; editors). Geological Society of America, Special Paper 407: 73-95. doi:10.1130/206.2407(04). 
Melnick, D.; Charlet, F.; Echtler, H.; Marc De Batist. 2006c. Incipient axial collapse of the Main Cordillera and strain partitioning gradient between the Central and Patagonian Andes, Lago Laja, Chile. Tectonics, 25, TC5004. doi:10.1029/2005TC001918.

Moreno, H.; Lahsen, A. 1986. El Volcán Callaqui: ejemplo de volcanismo fisural en los Andes del Sur. Revista de la Asociación Geológica Argentina 42: 1-8.

Morley, C.K.; Nelson, R.A.; Patton, T.L.; Munn, S.G. 1990. Transfer zones in the East African Rift System and their relevance to hydrocarbon exploration in rifts. American Association of Petroleum Geologists, Bulletin 74 (8): 1234-1253.

Muñoz, J.; Niemeyer, H. 1984. Hoja Laguna del Maule, Regiones del Maule y Biobío. Servicio Nacional de Geología y Minería, Carta Geológica de Chile 64: $98 \mathrm{p}$.

Nakamura, K. 1977. Volcanoes as possible indicators of tectonic stress orientation: principles and proposal. Journal of Volcanology and Geothermal Research 2: 1-16.

Naranjo, J.A.; Polanco, E. 2004. The 2000 AD eruption of Copahue Volcano, Southern Andes. Revista Geológica de Chile 31 (2): 279-292.

Niemeyer, H.; Muñoz, J. 1983. Hoja de La Laja, Región del Biobío. Servicio Nacional de Geología y Minería, Carta Geológica de Chile 57: 52 p., escala 1:250.000.

Pasquarè, F.A; Tibaldi, A. 2003. Do transcurrent faults guide volcano growth? The case of NW Bicol Volcanic Arc, Luzon, Philippines. Terra Nova 15: 204-212.

Pesce, A. 1981. Estratigrafía de las nacientes del río Neuquén y Nahuever, Provincia del Neuquén. In Congreso Geológico Argentino, No. 8, Actas 3: 439-455. San Luis.

Potent, S. 2003. Kinematik und Dynamik neogener Deformationsprozesse des südzentralchilenischen Subduktionssystems, nördlichste Patagonische Anden $\left(37^{\circ}-40^{\circ} \mathrm{S}\right)$. Thesis (Unpublished), University of Hamburg: 169 p. Germany.

Radic, J.P. 2006. Anistropías de basamento como control estructural del volcanismo en el Complejo Volcánico Chillán. In Congreso Geológico Chileno, No. 11, Actas 2: 1-15. Antofagasta.

Radic, J.P.; Rojas, L.; Carpinelli, A.; Zurita, E. 2002. Evolución tectónica de la cuenca terciaria de Cura-
Mallín, región cordillerana chileno argentina $\left(36^{\circ} 30^{\prime}-\right.$ $\left.39^{\circ} 00^{\prime} \mathrm{S}\right)$. In Congreso Geológico Argentino, No.15, Actas 3: 233-237. Calafate.

Ramos, V.A.; Folguera, A. 2005. Tectonic evolution of the Andes of Neuquén: Constraints derived from the magmatic arc and foreland deformation. In A case study in sequence stratigraphy and basin dynamics (Spalletti, L.; Veiga, G.; Schwarz, E.; Howell, J.; editors). Geological Society of London, Special Publication 252: 15-35.

Rapela, C.W.; Llambías, E.J. 1985. La secuencia andesítica terciaria de Andacollo, Neuquén, Argentina. In Congreso Geológico Chileno, No. 4, Actas: 458-488. Antofagasta.

Rosendahl, B.R. 1987. Architecture of continental rifts with special reference to East Africa. Annual Review of Earth and Planetary Sciences 15: 445-503.

Stern, C. 2004. Active Andean volcanism: Its geologic and tectonic setting. Revista Geológica de Chile 31 (2): 161-206.

Suárez, M.; Emparan, C. 1995. The stratigraphy, geochronology and paleophysiography of a Miocene freshwater interarc basin, Southern Chile. Journal of South American Earth Sciences 8 (1): 17-31.

Suárez, M.; Emparan, C. 1997. Hoja Curacautín, Regiones de la Araucanía y del Biobío. Servicio Nacional de Geología y Minería, Carta Geológica de Chile 71: 105 p., 1 mapa 1:250.000.

Tibaldi, A. 1995. Morphology of pyroclastic cones and tectonics. Journal of Geophysical Research 100 (B12): 24.521-24.535.

Vergani, G.; Tankard, A.J.; Belotti, H.J.; Welsnik, H.J. 1995. Tectonic Evolution and Paleogeography of the Neuquén Basin, Argentina. In Petroleum Basins of South America (Tankard, A.J.; Suárez Sorucco, R.; Welsnik, H.J.; editors). American Association of Petroleum Geologists, Memoir 62: 383-402.

Wertheim, J.A.; Charrier, R.; Croft, D.A.; Flynn, J.; Wyss, A.R. 2003. Fossil mammals and Ar/Ar radioisotopic dating from Laguna del Laja, Chile: Implications for post-Neocomian tectonic history. Geological Society of America, Abstracts with programs, Special Meetings 70-97.

Zanettini, J.; Méndez, V.; Zappettini, E. 1987. El Mesozoico y Cenozoico sedimentario de la comarca de los Miches. Provincia de Neuquén. Revista de la Asociación Geológica Argentina 42 (3-4): 338-348. 